\title{
فضاءات الرؤية وآليات المنهج البمالي على وفق استراتيجيات التفكير في الخطاب التشكيلي
}

\section{أ.م.د وسام أحمد شهاب / مركز دراسات الكوفة / جامعة الكوفة م. نورسر صيدر محمود / كلية التربية الأساسية / جامعة ديالى}

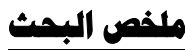

تؤكد الاتجاهات الحديثة في الميدان المعرفي النقاي على ضرورة إكساب المتلقي مهارات تمكنه من التظلب على الصعويات بإنتاج صور

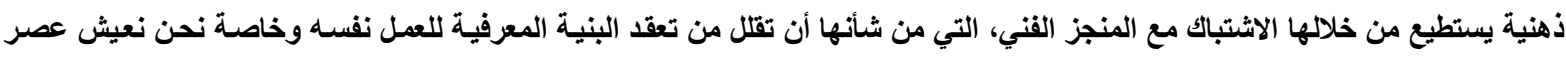

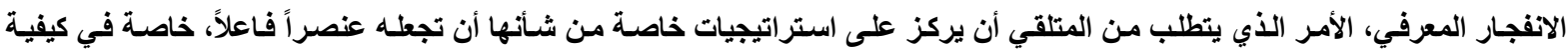

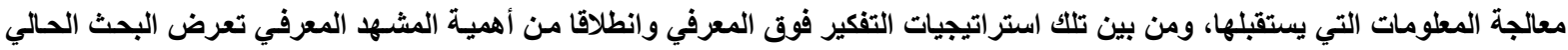

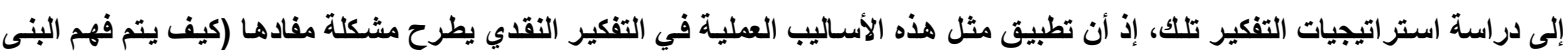

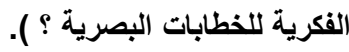

لمعالجة هذه المشكلة، قام الباحثان بدراستهم الموسومة (البنى الفكرية للنطابات البصرية (بيت موندريان) أنمونجا). ولأجل التصدي

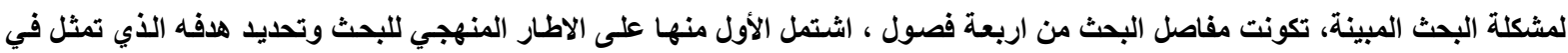

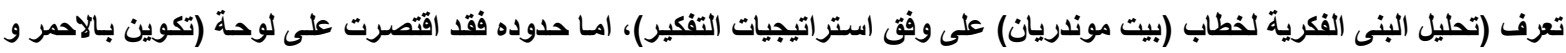
الازرق و الاصفر) للفنـان (بيت موندريان) انمونجا للاراسة الحالية، إضـافة الى تحديد استراتيجية التفكير فوق المعرفي في تحليل عينة

امسا الفصل الثاني (الاطار النظري) فقد تضمن مبحثين الاول منها (مفهوم التفكير فوق المعرفي) والثاني اختص بدراسة (إستراتيجيات

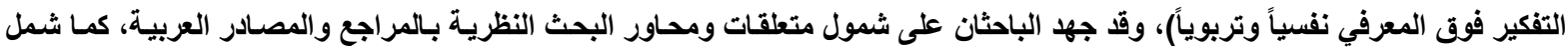

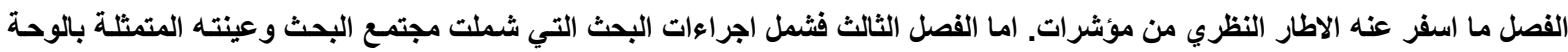
الفنان (موندريان) (تكوين بالاحمر و الازرق و الاصفر) لتمثل انموذج البحث وشمل ايضاً اداة البحث التي تمثلت باستراتيجيات التفكير فوق

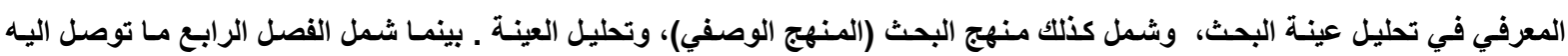

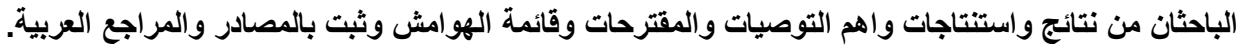

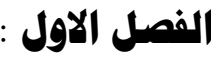

أولاً: مشكلة البحث

ان الكم الهائل من المشكلات التي بدأت تفرض هيمنتها نتيجة التسارع المعرفي ، جعلت من التفكير والتمتع بمهار اته ضرورة حتمية للتمكن من تلك المشكلات التي باتت أحدى ملامسح الألفية الثالثة، لذا فإنه من الواجب مئب اعـادة النظر في أسـاليب التحليل، وطريقة تفكير المتلقي، وان المهح حقا هو أن يتعلم كيف يفكر في الطرق الفعالة التي ينبغي عليه التفكير من خلالها بقصد تتمية وأطلاق طاقات الابداع لديه، و الخروج بـه من ثقافة تلقي المعلومات إلى ثقافة بناء المعلومات وتحو يلها إلى معرفة تتمثل في أكتشاف العلاقات في العمل الفني بمـا بمكنه مـن الانتقال مـن مرحلـة المعرفـة إلىى مرحلـة فوق المعرفـة (melacognition) و المتمثلــة في التأمـل في سي المعرفة، وفهمها وتفسير ها و أستكثاف أبعادها من خلال استر اتيجيات من البحث و التقصي.

يرى الباحثان ان عملية تغيير وتطوير قدرات المتلقي تعد معادلة ذات طرفين أساسيين أحدهما التفكير، و الاخر آليات التحليل ويساعدهاو وعي المتلقي بتفكيره ومشاركته في التقام العلمي والفني، ويمثل الهدف الاسمى لعملية التحليل والنقد الفني، حتى يكون قادرا إلى التوصل إلى المعرفة بنفسه، ومن خـلال العمليات العقلية أو 
النشـاطات الذهنيـة التي يمارسـها لتكوين تصـورات تطابق المتخيل في البدايات الأولى و التـي تمثنل مـا يريــ استظهاره المتلقي أثناء الاسترسال بين الدلالة أو التصور و التركيب الذي يتمثل في تصرف المتصسور في ذلك المنوال العرفاني المؤمثل في الموقف الإبداعي ذو المعنى المقصود لينتج كل مرة تركيبا بنوع مخصوص. ان الاعم الاغلب من المتلقين في مؤسساتتا التعليمية لا تتوفر لديهم هذه المهارة بسبب أن التعليم فيها موجـه

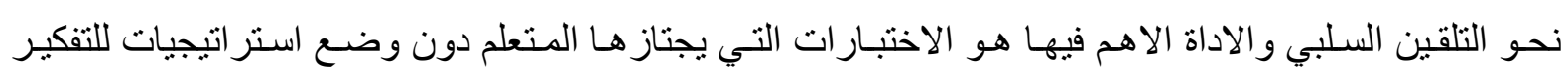
و التأمل.

ومن ذلك تتلخص مشكلة البحث في التسـاؤل الآتي: (كيف يتم تحديد فضـاءات الرؤيـة وتطبيق آليات المنهج الجمالي وفق استر اتيجيات التفكير ؟ ). أهمية البحث والحاجة إليه:

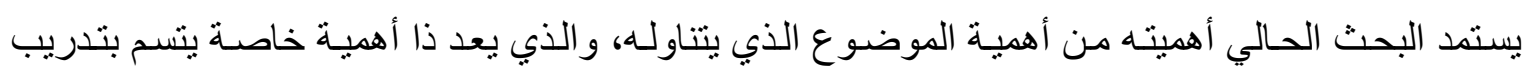
المتعلمين على استر اتيجيات التفكير فوق المعرفي، وهي أحدى الأساليب المعرفية الهامة التي تسهم بشكل فاعل في تتمية المساحة المعرفية التأملية لاى المتلقي و التي من شـأنها ان تنظم المدركات والخبرات وتكوين وتنـاول المعلومات، أي انها طريقة مميزة أو عادة يمارسـه المتعلمين في تكوين وتتـاول المعلومـة، وأن تعلم مثنل هذه الاستر اتيجيات من شـأنها أن تستقر في حافظة المتعلم المعرفية وتتسع ممـا يجعل لها جذوراً عميقة في بنية الثخصية في جوانبها المختلفة، وبذلك تحول الجهود التي تبذل لتدريس الدروس الأكاديمية من حالة الإحباط و التلقي السلبي الى نجاح و اتساع متوقف إلى حد كبير على كفاءة المتعلم نفسـه، معتمداً على قدرتهم في مر اقبـة تعلمـه على أسـاس التخطبط والاستيعاب و التقويم ودمـج تلك الاسـتر اتيجيات في آليـات التحليل و النقد الفني وتطبيقها على الأعمال الفنية، وام الدراسة الحالية توفر الاستفادة من الممارسة التطبيقية لاستر اتيجيات التفكير فوق المعرفي وعلاقته باكتساب مهار ات عقلية تمكن الطالب من تكوين تصور ات ذهنية. هدف البحث: يهذف البحث الحالي الى تعرف: تحليل البنى الفكرية لخطاب (بيت موندريان) على وفق استر اتيجيات التفكير حدود البحث : (1)

او لاً: لوحة (تكوين بالاحمر و الازرق و الاصفر) للفنان (بيت موندريان) أنموذجا للار اسة الحالية ذلك للأسباب الآتية:

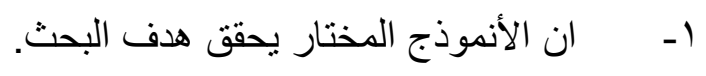
r- اتسام اللوحة المختارة بحسن الصنعة ومكانتها العالمية.

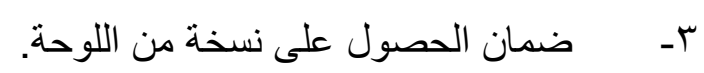
ثانياً: استر اتيجية التفكير فوق معرفي تحديد المصطلحات:أو لاً: التفكير فوق المعرفي: يعرف بـ : "التفكير حول التفكير والذي يتضـمن عمليـات التخطيط للمهــة التي سيقوم بها الفرد ومن ثم مر اقبة استيعاب هذه المهمة، وأخيراً تقويم مدى التقدم لهذه المهمة". (') ويعرف بـ: "أنها 
جوهر التعلم التـألمي الذي يتكون مـن التخطيط، والمتابعة، و التقويم".(؟) كمـا يعرف بأنـه: "الادر اك الداخلي للقدرات المعرفية وتشمل الادر الك الذاتي لعملية التعليم واستر اتيجيات الاسترجاع، وقد أطلق على هذا المصطلح

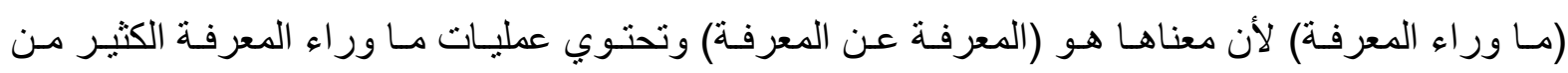

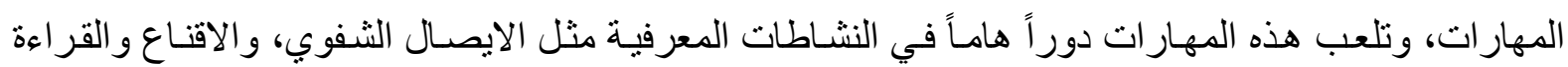

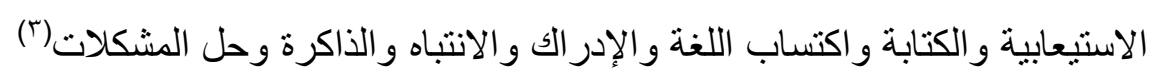

التعريف الإجر ائي: مجموعة من الاجراءات والسلوكيات العقلية التي يدرب عليها أفر اد المجموعة التجريبية بهدف إكساب المعرفة بالعمليات الذهنية، و القدرة على ترتيب وتعتيم اسـاليب التعلم والتحكم الذاتي قبل التعلم، و إثناءه، وبعده من خلال القيام بالتخطبط والمر اقبة والتعتيم للأداء. ثالثاً: استراتيجيات التفكير فوق المعرفي: نعرف: بـ: "هي مجموعة الاجر اءات والخطوات التي يقوم بها كل من المعلم والمتعلم لتوفير بيئة تعليمية مناسبة لتعليم وتعلم مهارات التفكير فوق المعرفي (التفكير ماوراء التفكير

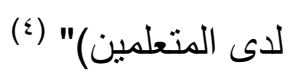
التعريف الإجرائي:هـي القدرات التي يحتاجها الطالب لتحقيق أعلى مسـتويات الكفـاءة، والمتمثلـة في أعلى مستويات تصنيف بلوم المعرفي (التحليل و التركيب و التقويم).

الفصل الثاني:

\section{المبحث الأول ( مفهوم التفكير فوق المعرفي )}

تحتل عمليـة التفكير في البيئة التعليميـة مكانـه هامـة، كونـه يمكن الفرد من إيجـاد حلول مناسبة لمشكلات

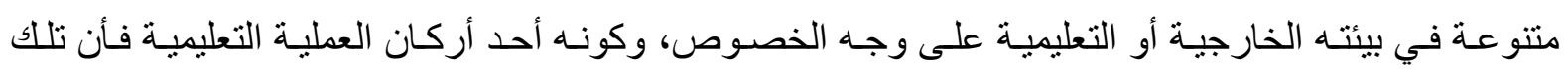
المو اقف تتكرر لديـه باستمر ار إذ تشكل مجمـل تجربتـه الدراسـة، ممـا يؤسس بالضـرورة إلى منظومـة عقليـة أساسها التجريب و التركيب، لذا يعد التفكير عنصر ا أساسيا في البناء العقلي والمعرفي، ويتسنم التفكير مكانة سامية بين سـائر العمليات العقلية ويتصف بـالرقي وشدة التعقيد، ويحمل معساو لاً معرفيـة بستطيع المرور إلى ولى باطن وخفايا الأشياء و المو اقف والحفر بها بمـا يمكنه من أتيـان المعالجـات واعادة إنتاج المعارف و المعلومـات

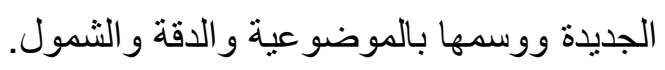

ان تو الد الافكار على شكل صور ذهنية في عقل (المتعلم) تمكنه من بنـاء موضوع التخصص وحقل بحثه

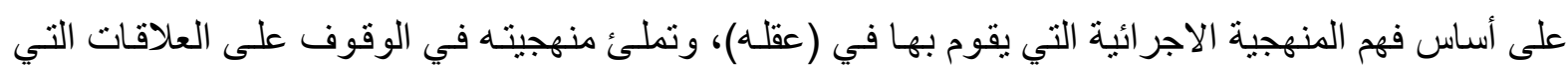
تربط الأشياء ببعضها والوصول إلى الحقائق، لذا يعد التفكير نشاطاً ذهنياً يتمثل في اسلوب حل المشكلة، و هذه القدرة تتمو وتتطور على نحو ارتقائي وتدريجي يحكمه التأسيس المعرفي لهذه المقدرة بنطلق من ضبط لمفهوم القدرة العقلية.

ان التفكير لا ينمو تلقائياً لأنهه عملية لا تكتسب بشكل بشكل عفوي أو نتيجة عرضية من خـلال محساو لات

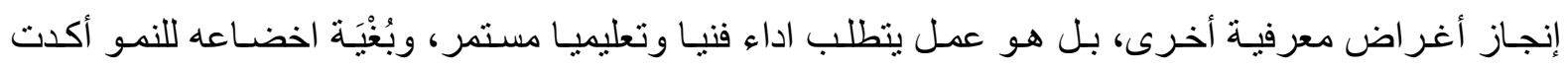

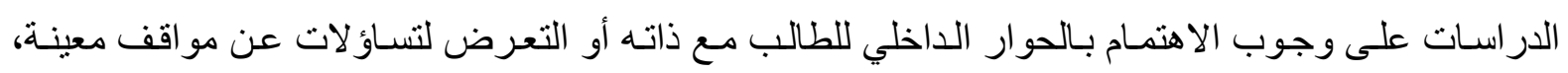


يحاول إيجاد أجابات هادئة ولا يأتي من خلال حفظ المعلومات واسترجاعها فقط، بل بتطلب تعليما منظما هادفا وتدريب مستمر لتتمية مهارة التفكير، وتنوعت أنواع التفكير لتنوع الخطاب المعرفي الذي ينطلق من وجهة

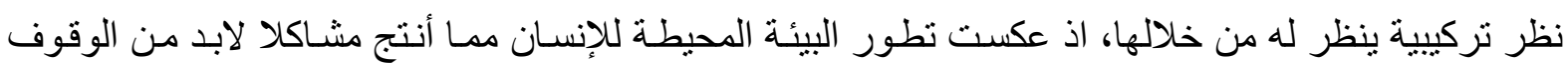

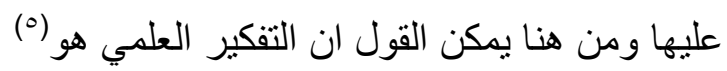

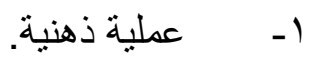

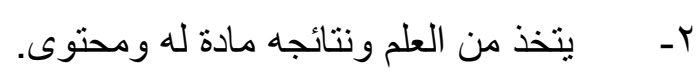
r- بعتمد على العقل و البر هان المقنع بالتجربة.

يتعامـل التفكير بـالادر الك ويمثنل الادر اك التنظيم الذاتي للفرد و النظـام الثــامل للمعلومـات و المتغيرة ذات تصور ات شكلية المتركزة في (المـخ) باعتباره وحدة جمع المعلومـات و الذي يقوم بمقارنـة المعارف المدركة بالحجم التركيبي للمشكلة، فالملفوظ الناتج عن عملية التفكير يشكل سلوك في سياق الموقف اذا تو افر لديه سياق يوضع فيه، أب نموذج مسبق قام (المخ) بإدر اجه ضمن مجمو عة نماذج. تتعدد لغة التفكير، مما ينتج تنو عاً في خيارات التعامل معها ويمكن حصر لغات التفكير على النحو الاتي: ا - اللغة البصرية: ويتم فيها استخدام الصور و الرسومات و المخططات و المجسمات و المنظر ثنائي الابعاد. r- اللغة اللفظية: ويتم التعاطي مع الكلمات، الوصف، الكتابة، الكلام، التعميمات.

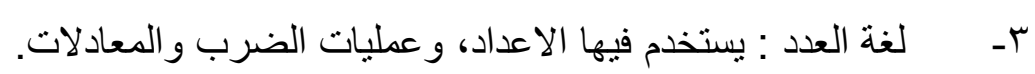

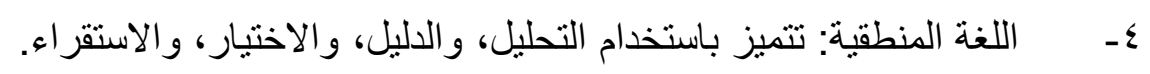
0ـ اللغة العاطفية: يستخدم فيها الاحاسيس و المشاعر و الوجدان والار اء، والجانب الإنساني.

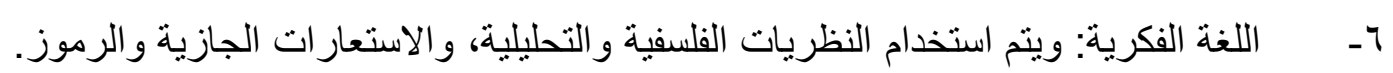
ان هذه اللغـات المتعددة للتفكير، أنمـا تؤسس مدركات ذات صـلة بغرض معين، يمكن استخدامها بحسب مهارة الفرد في التفكير، إذ تنقسم مهار ات التفكير عند الأفراد إلى نوعين أولهما مهار ات التفكير الأساسية وهي

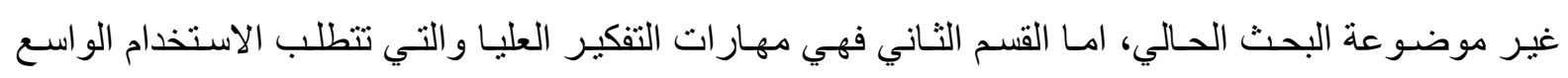
و المعقد للعمليات العقلية، وعلى هذا فهو يرتبط بمقاصد ذلك الاستعمال و المقامات التي يجري فيها، وتدخل في تكوينه عدة مكونات هي التفسير والتحليل التام للمعلومات ومعالجتها بالخزين المعرفي السـابق المدرك ومقارنتهـ بالمدرك اللاحق قيد الأرسال ثم حل المشكلة أي أصدار الحكم أو اعطاء الاراء، ويتم الوصسول الى النتائج من خلال حزمة من المقاصد تكون مثابة معايير ومحكات ودر اسة المستويات المتعلقة باختبار ات الفرد ويثمل هذا النوع من المهارة، مهارة التفكير ما فوق المعرفي ويلعب المثير دوراً هامـاً في نوعية الاستجابة اذ أن المثير يحدد صفات نوعية التفكير ومقدار المعالجة العقلية التي تحدث الفاصل وتجد التر ابط بين المثير من جهة وبين

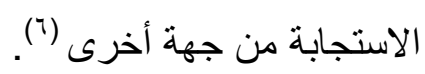


ظهر مفهوم التفكير فوق المعرفي في بداية السبعينات ليضيف بعداً جديداً في مجال علم النفس المعرفي ويفتح آفاقاً واسعة للدر اسات التجريبية و المناقثات النظرية في موضو عات الذكاء و التفكير و الذاكرة و الاستيعاب ومهار ات التعلم وقد تطور الاهتمـام بهذا المفهوم في عقد التمانينات ولا يزال يلقي الكثير من الاهتمـام نظرا

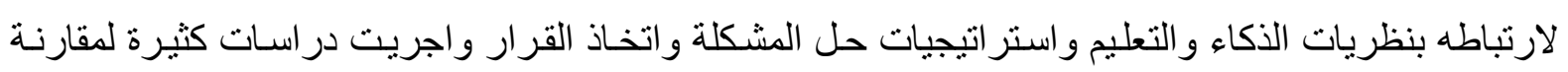
مستويات مهار ات التفكير فوق المعرفي لدى العـاديين والموهوبين و الافر اد الذين يعانون من قصسور عقلي و واظهرت نتائج الدراسات ان الاطفال والافر اد الذين يعانون من قصور عقلي يتصرفون بصورة متكررة وكأنهم غير واعين لما ينبغي عمله أو اتباعه من استر اتيجيات أو اسـاليب لحل المشكلة كما ان ادارتهم لسلوكهم الذاتي في مواجهة منطلبات حل المثكلة ليست فعالة كما هو الحال لدى العاديين والموهوبين.

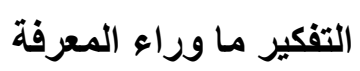
يعد التفكير ما وراء المعرفي من أكثر موضوعات علم النفس حداثة رغم الإرث التأريخي والذي مر البحث

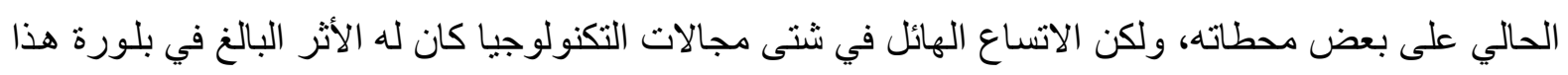

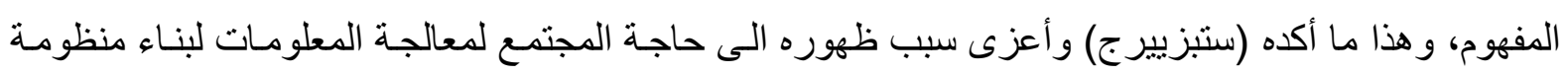
التحكم بالمعرفة ذاتها وفق خطوات علمية هادفة لحل المشكلات وهذا النوع من التفكير ينتمي الى التفكير عالي الرتب اذ بتضمن مر اقبة تتسم بالنشاط لعملية المعرفة تتمثل بالتخطيط و المر اقبة و التقويم.

ان مهمة التفكير فوف المعرفي تتمثل بوعي الفرد وبإمكانياته وقدر اته على ملاحظة تنظيم الخزين المعرفي المتمثل بالمعرفة القبلية، لذا تنوعت التعريفات التي تناولت التفكير الماور اء المعرفي ، والتي تتشير الى " قدرة الناس على الفهم والتحكم بعمليات التفكير الخاصـة بهم يظهر في سباق عملية معالجة المعلومـات بهدف بنـاء نموذج لعمليات التحكم بالمعرفة، ويمثل أيضا وعي الفرد و إدر اكه لعمليات المعرفة وقدرته على تتظيم وتقييم

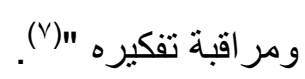

في هذا الصدد يشير (flavall) إلى وجوب التميز بين انواع التفكير المختلفة وبين التفكير فوق المعرفي، اذ لابد إلى الالتفات إلى نبع المعرفة الماور ائية والتي تستند الى حقائق دفينه في دو اخل الأشياء ذاتها، أي مر اقبـة تمثنات الأشياء في ذات الفرد يتابعها تحقيق وحكم فيما كان الفرد يستطيع أنجاز شيء بمثابـه أو لا يستطيع وبذلك يحدد انجاز المهمة أو عدم أنجاز ها ويرى (فلافل) ان معرفة مـا وراء المعرفة لابد وأن تمر في ثناث مر احل تحدد الأولى معرفة الثخصية والثانية معرفة المهمة أما الثالثة الوقوف على معرفة الكميات الهائلة من المعلومات التي من الممكن الوقوف عليها، ويجمع الدارسين رغم تعدد التصنيفات لمكونات التفكير، على ثلاثنة

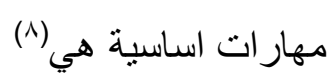

التخطيط Planning :- ويتمثل في أن يكون للفرد هدفاً ما موجهاً ذاتياً، أو يتم تحديده له، وأن يكون لديه خطة لتحقيق الهدف وتتضمن ان يطرح الفرد اسئلة مثل: ما طبيعة المهرة؟ وما هو الهدف؟ وكيف يعي الفرد بعض فئ العبارات الدالة على التخطيط مثل حاولت أن أفهم العمل قبل ان أحاول حله. 
المر اقبة Monitoring: ويحتاج فيه الفرد الى آلية اختبار الذات لمر اقبة تحقيق الهدف وتتضمن ان يطرح الفرد

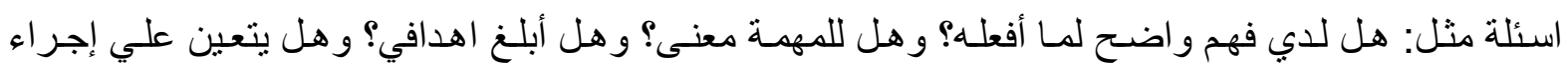
تغيير ات؟

التقويم Evaluation: ويتمثل بتقيم المعرفة الراهنه، ووضـع الاهداف واختيـار المصـادر ، ويتضـن ان يطرح الفرد أسئله مثل: هل بلغت هدفي؟ وما الذي نجح لاي؟ وما الذي لم ينجح؟ وهل أقوم بعملي بشكل مختلف في المرة القادمة؟

ان الاتسام بصفة التفكير فوق المعرفي له المكانة الرفيعة في نفوس المتعلمين إذ يتصف الموصوف بذي تفكير فوق معرفي بميزات أهمها أنه يستطيع تطوير خطته العملية الخاصـة، أذ أنه يستطيع إبقاء هذه الخطية فاعلة حتى وقت طويل في ذهنه، بل الايفاد بتقييمها حال أكتمالها ولا يعمد إلى تطبيق ما تصـوره في ذهنه حسال حدوث التصور، أذ بعمد إلى حضور آلية للتطبيق تساعده في تنفيذ ما فكر فيه وتصوره بشكل تصور ات ذهنية، ولا يفوت الباحثان أن يذكر أن هذا الفرد تكون حالة استعداده لأستعادة التجربة أكثر من الفرد الذي لا يتسم بهذه

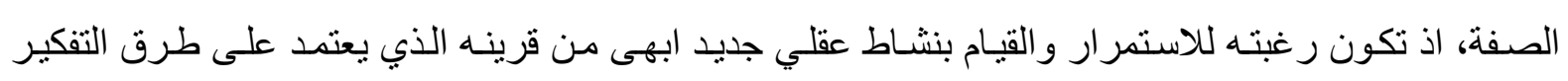

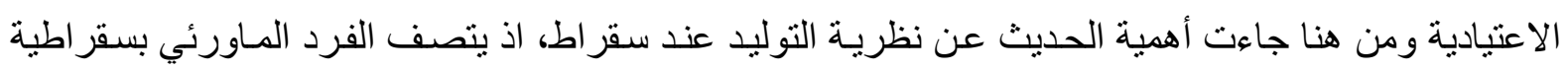

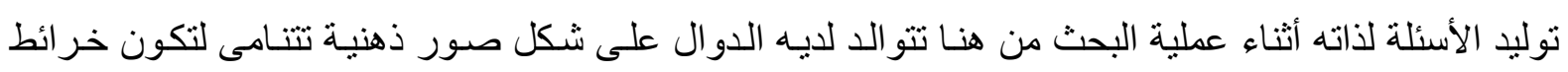
مفاهيمية وتكون هذه خط الثروع لتنفيذ المهمة، ان عملية التنفيذ مقيدة بشرط التصحيح ان لزم الأمر لذلك، فهي

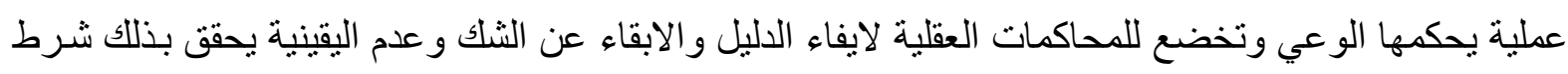

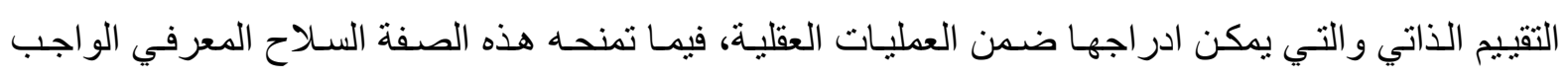

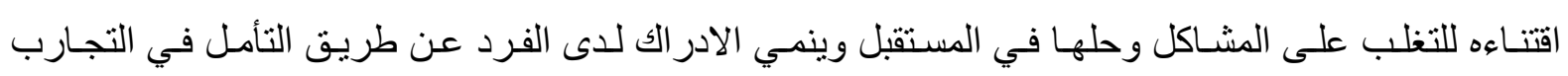
المعرفية التي مر بها وماينبغي القيام به في المواقف المماثلة (9).

ليس جميع الطلبة يمتلكون هذا النوع من التفكير المنظم, لذا سنقف في المبحث الثاني من هذه الدراسـة على الاستراتيجيات الواجب اتباعها لتمكين جميع الطلبة من الحصول على هذه الطريقة في التفكير المنظم.لان

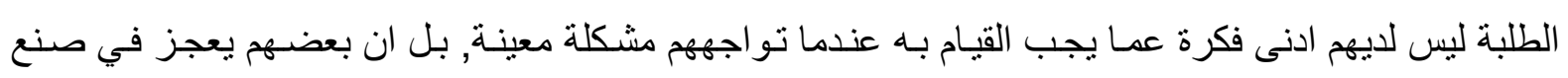

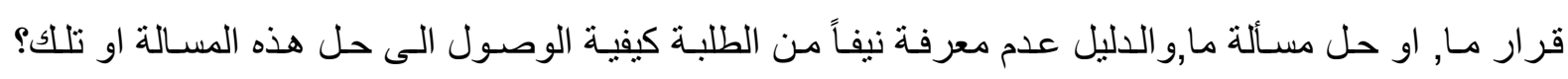

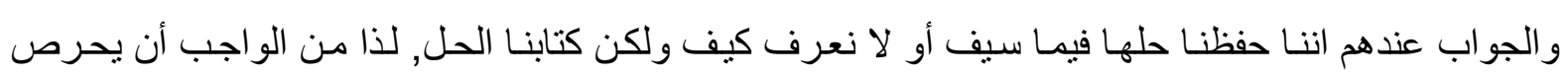

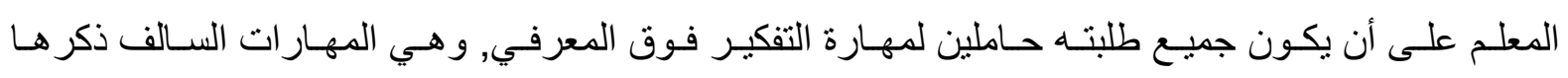

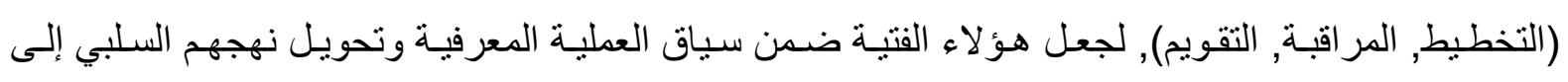
الإيجاب و ارتقائه إلى سلم ما ور اء المعرفة متمثلا بالتفكير .

إن من المفيد ذكره أن عملية التخطيط، تشعل التخطيط لعملية إعـادة التفكير بهذا النوع مرة أخرى وفي مو اقف جديدة، ومن خلال هذه الخطاطة تتوضح أن عمليـة التفكير فوق المعرفي اساسـها الأدراك بشقيه أدراك نو عية التفكير الملائمة للمشكلة أو الموقف والمشكلة كلاهما معاً، وللإدر الك أهمية بالغة أذ يقف مفتاح الأجابـات 
على أدر الك الأسـئلة، ولابـد المـرور بوصـف كامـل للمشـكلة في عقل الطالب وشـمعته (الـخ) أي أستحضــار الأستر اتيجيات الو اجب أتباعها في هذا النوع من التفكير مـع مر اجعة الذات عن كوامن المعرفة المحيطة لهذه المشكلة أو القريب منها مع ملاحظة خصوصية المشكلة وتحليل معطياتها وفلك شفرات علاقاتها المختلفة من هنا تبدأ عملية التعرف على الأسئلة وتهيئة الأدوات و المفاهيم ضمن بنية أستتناجية اساسها الوصف الكمي و النوعي المبدوء بأستفهام هل التفكير فاعل أم لا ؟ أن الاستفهام يولد إجابـة ذات صفة يقينية تتعدم فيها صفة الفوضوية، لان الحكم سيولد بالتأكيد موقف و الموقف يكمن في المحفظة المعرفيـة لدى الفرد، لذا أن من أخطر الاشـارات هي التي تمتلك أطارًا أحمر والتقويم احدى تللك الأشارات التي من الواجب الوقوف عندها وتأملها لأطلاق الحكم المبنـي على رصـانة الأستقر اءو والاستـدال المسـتند على الموائمـة المعرفيـة، أذ أن التخطبط يعتمــ على بنايـة المو اقف المدركة سابقاً والمثبوت صحتها بالتجربـة أي تفصيل ثوب كلي لكيان كلي، اذ يمكن جعل من العابر و المتغير قانونـا اساسيا يمكن الاستفادة منهه ويكون الاسـاس في الطروحـات النظريـة في حقل تجديد المعاني، وبذلك يشعر الفرد بالفخر في محاولة تصحيح مسـاره و أنتخاء الدقة في نتاجهم العقلي، ولابد من الاشـارة الى

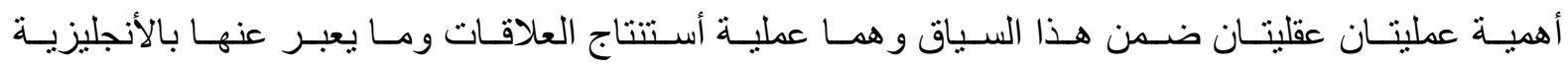
(Deduction of Relation) الأولى يتم من خلالها تبيان نوع التر ابط بين أي زوج من السمات أو الميزات للمـادة المحفوظة والوقوف على تمفصلات المتتالية في الجزء العميق من المـادة ونستدرج هذه المحاورة الاستفهامية في أطسار تكوين الصور الذهنية التي يكون مقامها الأول ضمن اطار العملية الأولى ومن جهة أخرى يؤدي الاختلاف والتناظر اللفظي مهمة هامة في تقرير معنى الحاجة الى تلك التصور ات بعد استدعاء المعاني من خزين الذاكرة يشترك بذلك التكوين التصوري في ذهن (الفرد) العملية الثانيـة في إظهار الصفات مـع علاقاتها ممـا يساعد في التعرف على عنوان ووظيفة المنتج الجديد، ونشير هنا الى أن هذه المتتالية العقلية تتدرج أيضـاً ضسن عملية

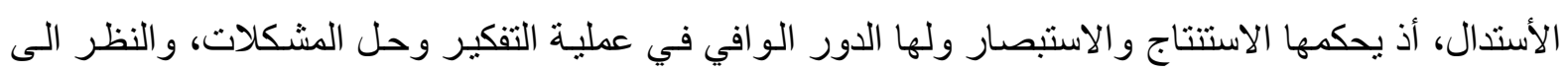
هذا النص كاملاً يدعونا الى الاستتناج بـأن الفعاليـة العقلية هي جوهي هر التفكير فوق المعرفي، حيث يبدأ الفرد بالتشكيل ثم المعالجة والتي تتتج على شكل تصورات ذهنية يقوم السلوك بترجمتها فيمـا بعد عن طريق الجهاز

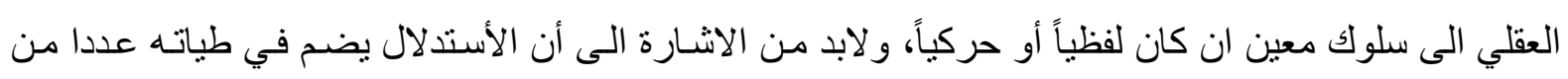

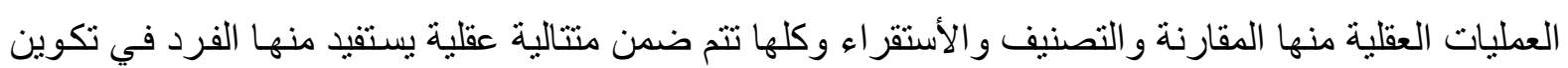
علله الصورية، إذ أن هذا الاختبار الأسلوبي لنوعية الصور المنتجة، والذي تتنمي فيه المحددات لتظهر الأفكار المو افقة على الموقف و لأسبابه ضمن حواريـة تكتمل فيـه أنماط السرد وتكتسي حلـة جديدة تكون بمثابـة الحل

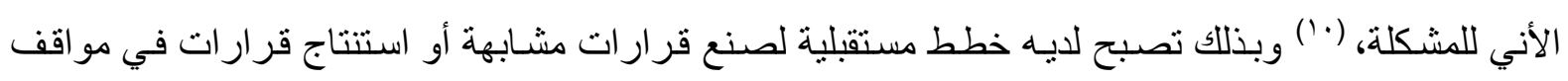
و مشاكل أخرى لأنه سيتبع حتماً نفس المتتالية التي اعتمد عليها فيما سبق، لذا حينمـا ننظر في هذه الاختبار ات فرات

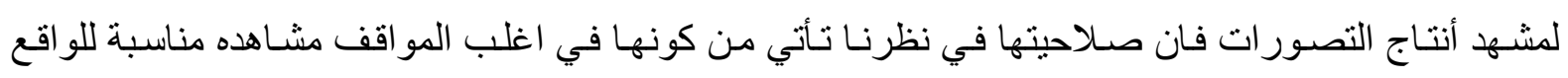
المشـكلي الذي تحاكيـه، فاسـتعمال العلامـات النصـية أو الصـورية الدالـة على الاختبـار والإفهـام والمقامسات 
و النوادر، كلها عن قصد في أستعمالها من قبل الفرد، وهي تدل في جانب أخر على الأختبار الأسلوبي للتفكير الذي يجسد قصد التموقع في التفكير ما فوق المعرفي على قصد يبتغيه في نوع الإجابة الناتجة. المبحث الثاني : إستراتيجيات التفكير فوق المعرفي نفسياً وتريوياً

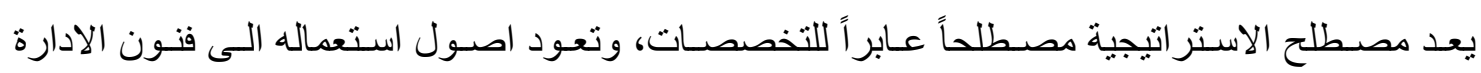

و الحرب و العلوم السياسية والاقتصسادية، والذي يهمنـا في ضبط المفهوم هو معرفة المقصود بـه أساسـاً حتى نستطيع وضعه في علاقة تخصصية مع التفكير، وتستطيع فهمها بشكل عام على أنها فعل واجر اءات وخطوات يقوم بها الفرد أبتغاء غاية محدده تكون بمثابة الهدف له، و لا يخلو هذا الطريق من صفة التخطبط على المستوى الذهني لدى الفرد، إذ لابد من تكوين تصـور يقوم على أساسـه الثطر الثاني من الستراتيج و هو الفعل والذي

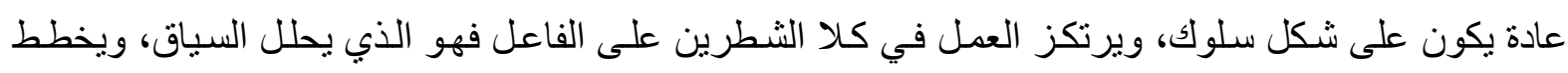
لفعله، ليختار من الإمكانات ما يفي بما يريد فعله حقاً، ويضدن له تحقيق أهدافه. ان نقل هذا المفهوم الى مجال (التفكير) يقود الى التداخل مع كثير من المفاهيم التي درستها ومنها علم النفس المعرفي والعلوم التربوية وغيرها من التخصصسات ليس من شـأن البحث الولوج فيها، أذ أنه من المفيد الابقاء على المعنى الذي يصفه علم النفس المعرفي وهو الذي اشترط وجود هدف معين، ومقام تردد، و غايـة للبت في الطروحات المعرفية والتي سنمر عليها في غياهب دراستتا هذه، و عليه فإن مصطلح (استراتيجية) لا

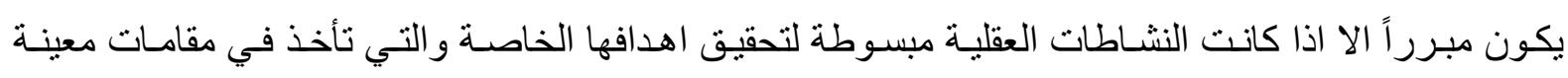
أهمية، و عكس النشاطات العقلية لتصب في بودقة التفكير المتسم بـالتخطيط و المر اقبـة والتقويم، وبمـا أن قو انين

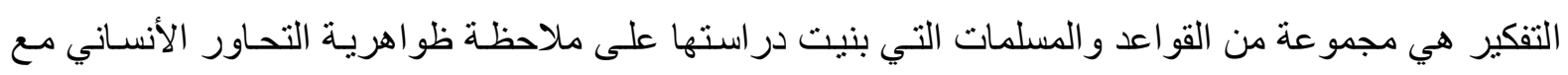
المحيط، فـإن الاستر اتيجية المستعملة فيها لا يمكن كثـفها الا في ظل معرفـة القو اعد، لذللك يـرى الباحثنان

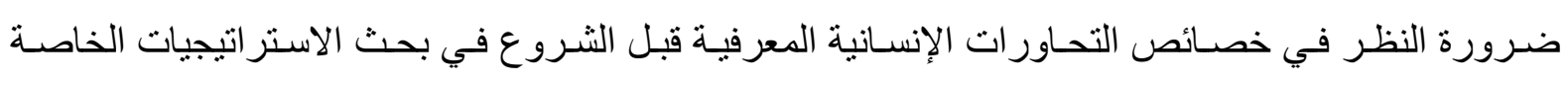
بالتفكير فوق المعرفي و التي هي قيد الفحص، لنكثف أهداف ومقاصد استعمال هذا النوع من التفكير عوضـا

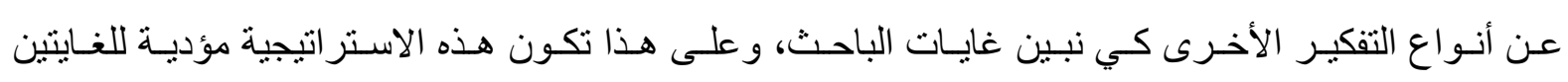

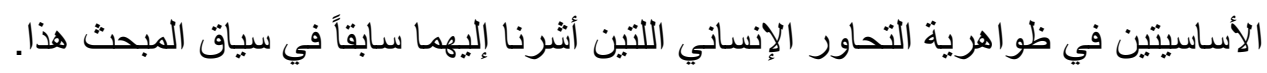

ان تنفيذ التخطيط الاستر اتيجي بطريقة عمليـة سليمة ضمن رؤيـة مبتكرة تعكس رؤيسة المؤسسـة التعليميـة ورسالتها وقيمها، إذ يتضمن هذا التخطيط الالتزام بصباغة الأهداف العامـة للمؤسسـة التربويـة، إذ أن هدف هذه

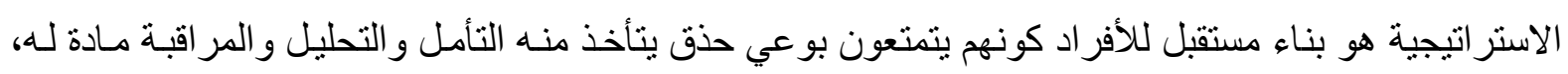
وينتج صور ذهنية قابلة للتحقيق، و عليه يجب ان تتصف هذه الاستر اتيجية بمو اصفات تضمن نجاحها في جميع المو اقف والمشكلات، إذ يجب أن تكون شمولية بحيث تضمن جميع المو اقف والاحتمالات المتوقع حدوثها في الموقف التعليمي، وأن تكون مرنه قابلة للتطوير بحيث توفر أمكانيـة تطبيقها على عينـات متعددة ومختلفة في نفس الوقت أو أوقات مختلفة، ومن الامور الهامة التي يجب تو افر ها منها أرتباطها بالهدف الدر اسي للموضوع المقرر التفكير فيه وفق استر اتيجية التفكير فوق المعرفي، كذلك تر اعي فيها طريقة التدريب ونمطية أي فردي 
أو جماعي، و لابـد من مر اقبـة الإمكانيـات المتاحة داخل بيئة التعلم، حتى يكون مبدأ تحقيق هذه الاستر اتيجية متاحة للتطبيق في جميع الأوقات.

من المعروف أن الطلبة يتفاوتون في الفروق الفردية فيما بينهم في استقبال المعلومـات وفي تتفيذ الأنشطة، و الأنشطة التطبيقية التي تعطى في الحصـة لتنفيذها من قبل الطلبـة وهذه الفروق يجب مر اعاتها في تحديد الاستر اتيجية، أذ من شأنها أخذ وقت يختلف بـأختلاف نوع الطلبة فبعضهم ينتهي من تتفيذ النشـاط بوقت أقل والبعض الأخر لا ينتهي من النشـاط لأسباب كثيرة منها عدم فهم الخطوات أو لوجود اعاقات تتعلق بالبيئة التعليميـة ذاتها، لذلك على واضـع هذه الاستر اتيجيات ان يضـع في الحسبان تصميم بعض الأنشطة الأثرائية

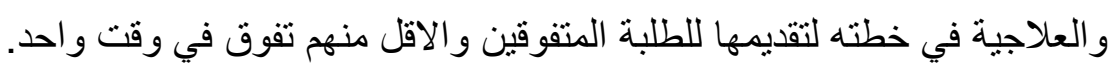

يستطيع منظم هذه الاستر اتيجية الى تضمين خطته بعض الانشطة الاثر ائيسة التي يتم تتفيذها من قبل الطلبة خارج الوقت المقرر للتمرين على التفكير فوق المعرفي، وتكون هذه الأنشطة مكملة ومرتبطة بالدرس ويمكن تنفيذها أما يدويا أو تطبيقها على الحاسوب، فمفهوم الأشكال الهندسية في مادة المنظور يمكن در استها في خارج الصف وعلى آلة الحاسوب، إذ يمكن دراسـة تكوين الأشكال والاعمـال التطبيقية للتعبير عن مواضيع مختلفة

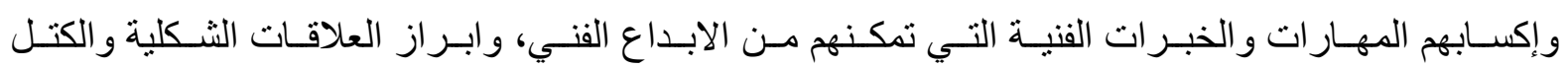

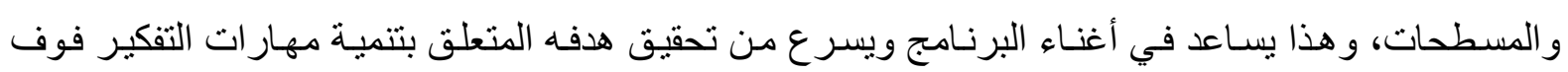
المعرفي لديهم، إذ أنه يدرك كيف نشأ الشكل، ومن خلال ذلك يستطيع أن يميز الطالب بين الأشكال الهندسية في

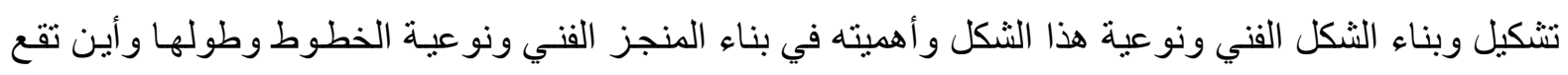
نقطة التلاشي، إذ إن استخدام هذه التقنيات المسـاندة في إيصـال علاقة الاجسام الهندسية مـع المحيط في داخل البناء الفني وما هي آلية بناءهـا و علاقاتها المتبادلة، مـع مر اعاة عرض بعض اللوحسات المشـابهة حتى يتمكن

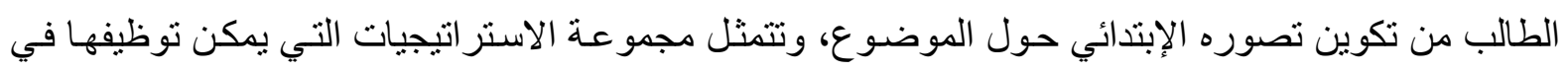

تعليم وتعلم مهار ات التفكير فوق المعرفي فيما يلي (1)

Self- Awareness

Self- Regulation

Self- Monitoring

Self- Assessment
استراتيجيات الوعي بالأات

$$
\text { استراتيجيات تنظيم الذات }
$$

استراتيجيات مراقبة الذات

إستراتيجيات التقييم الذاتي

تصف الأستر اتيجية الأولى قابلية المفرد المتعلم لإدراك المواقف التعليمية المتتوعة، وهل أنه مدرك

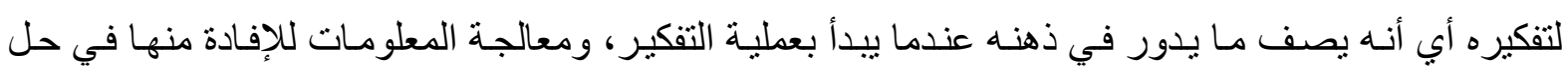
المشكلات، بينما تعالج الأستر اتيجية الثانية تنظيم تلك المعارف بحسب طبيعتها وتسابقها الزمني للفرد و أهميتها،

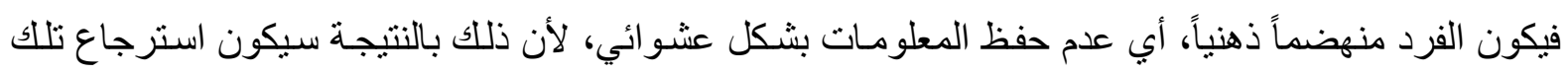

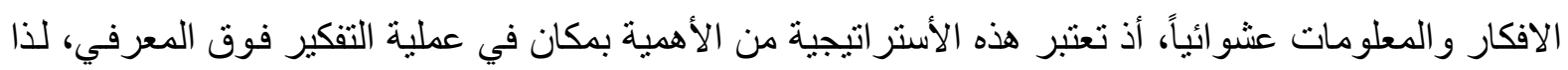


يركز الدارسون والباحثون في هذا النوع من التفكير على أعتياد الفرد المتعلم عملية التنظيم لذاته، أي تتظيم رقد حافظته المعرفية وترتيبها بالثنكل الذي يجعل أستدعاء تلك المعارف وتعريضـها للمحاكمات العقلية و التجريبية سلسـا هينـاً عليه، مـع شـرط وجود المر اقبـة الدقيقة لذات المتعلم حرصـاً من أنز لاقهه في يم التعند و الدغماتيـة، فالمر اقبة تعني توليف صبغ المضامين متجهة من الجزيئات الى الكليات غايته التحليل واستتباط المعنى وهو نشاط بنائي تركيبي استقرائي، حيث أن التفكير سلوك هادف لا بحدث في فر اغ و أنما يحدث في مو اقف معينة، لتحقيق الخطوة الأخيرة من عملية بناء التفكير فوق المعرفي وهي تقييم المنجز الدلالي و الحكم عليه بالاستفهام

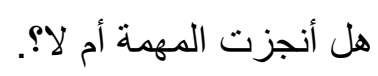

ان إنجاز المهمـة و التغلب على المشكلة معنـاه أن الفرد كان واعيا ومنظمـا ومر اقبـا لذاته، ولكن إذا كانت الإجابة موصوفة بالسلبية، فإن ذلك إثارة لحدوث عطب مـا في أحدى تلك الاستر اتيجيات ممـا يستدعي اعادة

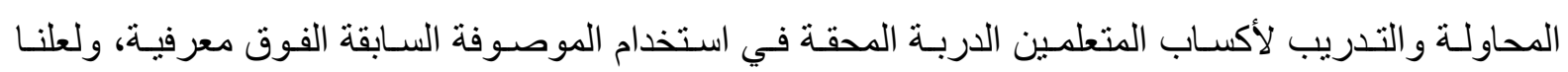
نستطيع ان نستجلي كيفية اتقان الدربه على التفكير فوق المعرفي عن طريق التأمل والتساؤل الذاتي و التفكير في

التفكير، ومن أمثلة الاستر اتيجيات الأخرى المستخدمة في إكتساب مهارة التفكير فوق المعرفي هي: (ז')

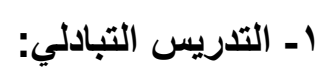

ان العملية التعليمية عملية تفاعلية، تتم عن طريق التفاعل المتبادل في قاعة الصف، بين المعلم والمتعلم من جهة وبين المتعلمين من جهة ثانيـة، وتتم هذه الخطوة عن طريق طر ح مشكلة معينة يقوم بحلها المعلم،

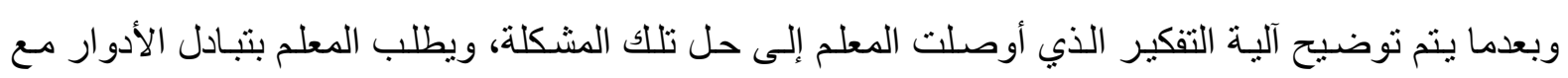
الطالب فيطلب من الطالب تدريس مفهوم معين أو أن يحل مشكلة معينة، ويعبر الطالب بالكيفيـة التي يفكر بها

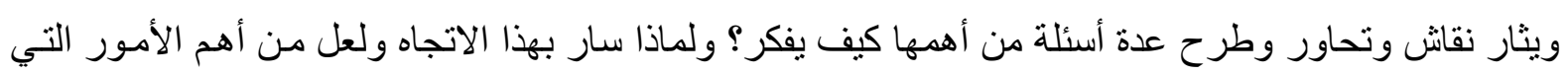
تتمي عند الطالب الثقة بالنفس هي المحاورة الدائمة بينه وبين المعلم أو بينه وبين الطلبة المتدربين، إذ أن الدربـه على المحاورة تمنح صـاحب الخطاب الذي يلفظ بـالنص المعرفي سري كان أم صـوري أو أي هويـة معرفية يملكها يمثل أولى الخطوات الأمامية للبحث في أنمـاط تلفظه ويفصـح عن ملامـح هذه الذاتيـة ومحاولتة ربطها

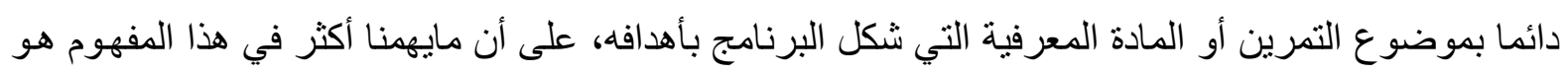

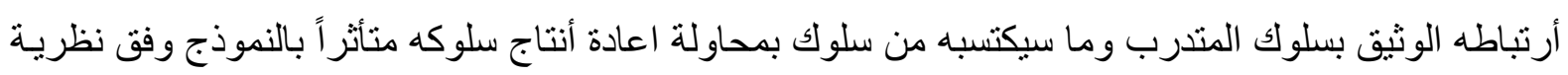

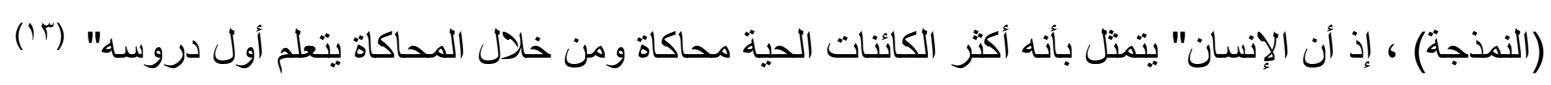
لا يفوتتا ذكر أهمية الإنتباه في التدريس التبادلي، ومحاولة ابقاء المتدربين ضمن دائرة الإنتباه، وذلك من

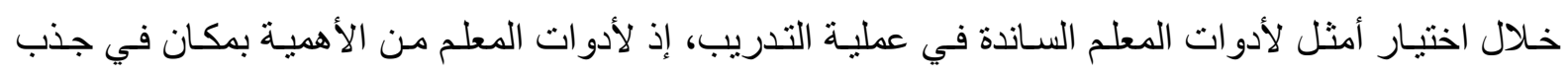
المتدرب لها كونها تكون شامله تسـاعد المعلم من الوصـول الى الهدف المرجو تحقيقه من البرنـامج بأقل جهد

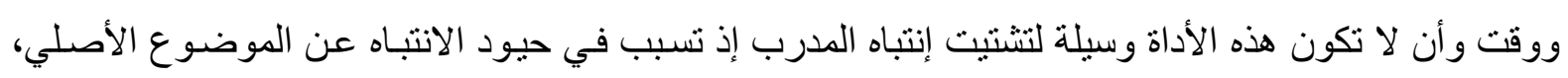
وأن كان الموضوع يتسم بالثائقية، إذ ترى المتدربين شـاردي الذهن و الابتعاد عن الاستطر اد وضرب الأون الأمتلة الكثيرة، إذ " غالباً ما يكون مر اعاة إلى حيود الانتباه عن موضو عه الأصلي، حتى و أن كان وسيلة من وسـئل 
الايضاح الا انه يشغل السامعين عن الموضوع الرئيسي، فأذا بهم قد خرجوا من الدرس وهم يتذكرون الأمثلة

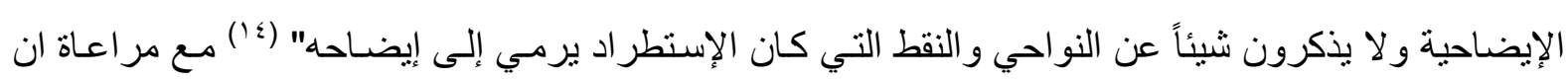

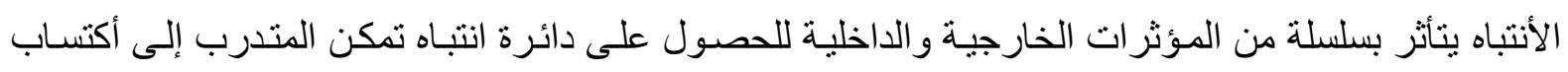

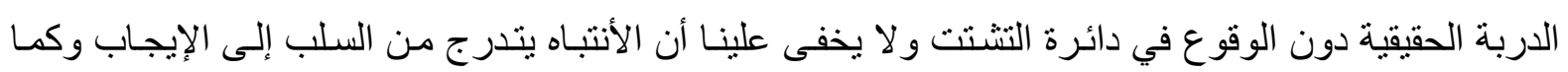

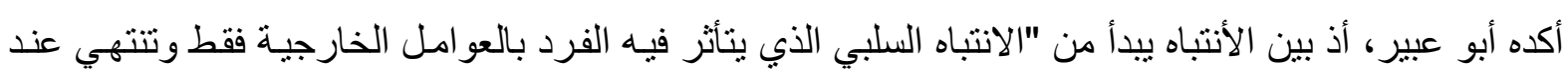

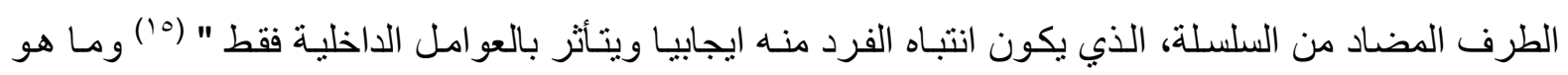
موضح في الخطاطة الأتية:

ان الطبيعة الأدميـة تفرض في التعليم مبدأ التعزيز، وخير مـايوظف في التدريس التبادلي، على أن إثنار الباحثان إلية في سياق العملية التعليمية وأهميته في مقام السلوك الخاص بالمتدرب ومقام توليد استر اتيجيته الخاصة التي تدخل في تكوينها عدة أجز اء ومكونات، وليتبين لنا هذا المفهوم بوضوح أكثر نشير إلى النظريـات

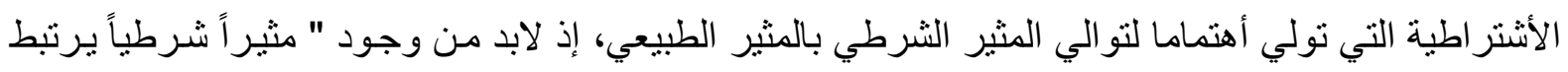

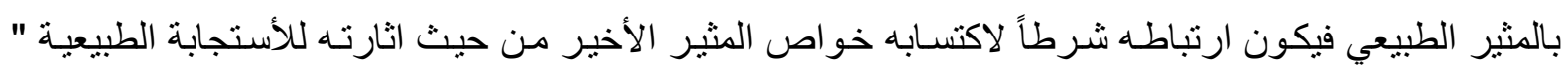

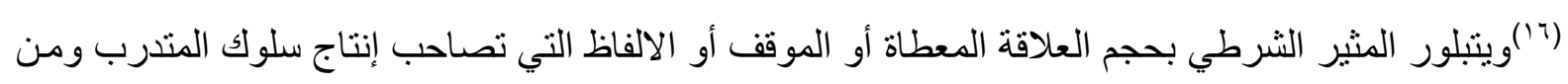
بين تلك الالفاظ قد أجيز بعضها مثل ( أحسنت، ممتاز ، رائع، وفقلك الله) الى غير ذلك من الرموز اللفظية التي تحقق التعزيز لديه، مما يؤثر بالثكل الإيجابي حتمـا في نوعيـة السلوك المنتج و الذي يسـاعد في انثـاء مفكرته

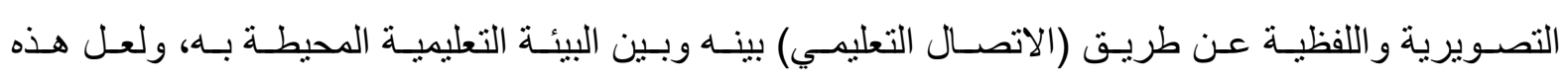
الاستر اتيجية الأولى من ستر اتيجيات تتمية مهار ات التفكير فوق المعرفي يشترك مـع الأستر اتيجية التاليسة وهي وهي

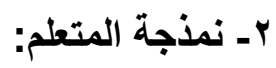

ان دور المعلم لا يقف عند حد تعليم المتدرب تقليده في ألياته لحل المشكلة فقط، الا ان هناك وجهاً أخر يحتاج إلى المناقشة و الوقوف عنده حتى تتبلور فكرة تكوين استراتيجية خاصـة لتنمية تلك المهارة، ونعني بذلك علاقة المتدرب بالمشكلة ذاتها وعلاقة السلوك المنتج، ولكي نضمن حدود التفاعل على المعلم أن يثير عدة تساؤلات منها كيف يتعلم الفرد؟ كيف يحل المشكلة، وفي هذا الصدد يشير المعرفيون الى المعرفة تتألف من شبكات معقدة من المعلومـات وتصـفف المعلومـات بدور ها الى فئتين، الأولى منها صـريحة تتعلق بالحقائق

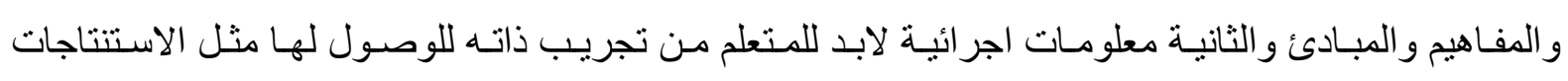
و التعميمات، لذا توجب على المعلم أن يلم بكيفية وصول المتدربين لتلك الأستنتاجات بنفسهم حتى يتمكنو ا من ملاحظة المو اقف المشابهة وتكر ار العملية من قبلهم إذ لا تقصر المشـاكل التعليمية على نوع واحد، وهو مـا تدربوا عليه أثناء عملية (النمذجة) التي تربوا عليها في الاستراتيجية الأولى، الحديث هنا يشير بشكل أخص إلى إلى

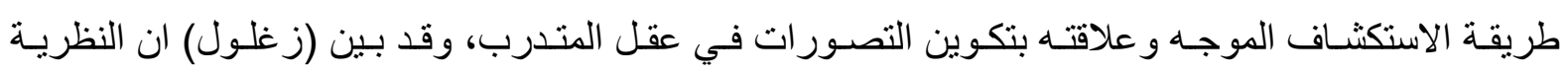

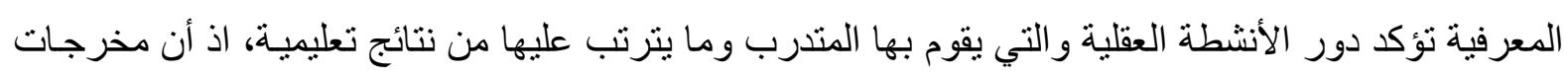


التعلم المستندة إلى محاولة الأستكثاف بعد أكثر عناصر عملية التعلم أهمية، ولا سيما أن هذه المعرفة هي التي

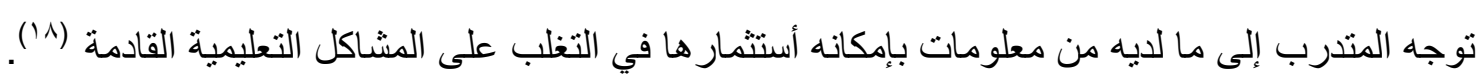
للاستكثاف ثلاثة أنواع هي:

أـ الاستكثـاف الموجه: Caided Discovery يعد هذا النوع أسلوباً مفضـلا في بعض المواقف التعليمية ومنهـا تعليم مهار ات التفكير فوق المعرفي، إذ تقوم أسئلة مثيره لاهنمـام المتدربين و إثارة مشكلات تستدعي الحل بدلاً من كيفية شرح حلها، وجعل المتدرب يمارس حلها بنفسه تحت مر اقبة المعلم و الوقوف على ولى

أهم مفصلاه (19)

الاستكثاف شبه الموجه: Semi Caded Discovery تقدم في هذا النوع مشكلة محددة للمتدربين وتعطى معها بعض التوجيهات و الإرشـادات، وتمنح فرصـة التفكير للمتدرب في التعامل مع هذه المشكلة، ولابد من

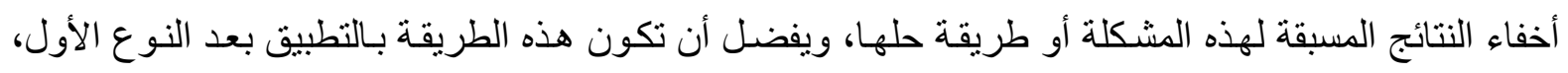
حتى يتمكن المتدرب مـن ربط المعطيات بين المشكلة في النوع الأول وبين النوع الثناني، لتكون لديـه دربـة حقبية بربط المشاكل و الوقوف على مسبباتها وبالتالي محاولة حلها بشكل كامل في مو اقف مشـابهة يمر بها المتدرب في حياته المعرفية اللاحقة، وهذا أساس تدريبه على مهارة التفكير فوق المعرفي.(·)

ب- بnguided Discovery : يعد الاستكثاف الحر من اضافية بين اضافيات أخر،

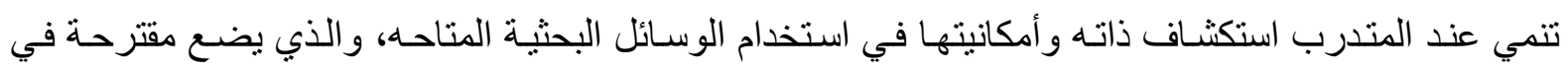
البحث من خلالها على تخوم علم البحث التجريبي وفقهه الخاص عن أشكال الحلول المناسبة لمشكلته التي لم يزوده المعلم بأي نوع من التوجيهات، أو أي نمط ملفوظي من شـأنه تقريب شكل الحل للمتدرب، فيبقى المعلم ير اقب شدة حر اك الردود السريعة والحوار المعرفي لدى المتدرب وتتوعها، معتبر ا أياهـا أليات عمل تقادمية توصل المتدرب إلى الحلول المناسبة، لذا هي طريقة يستحق أن يؤسس عليه اعتلالية تكوين المعـارف التي

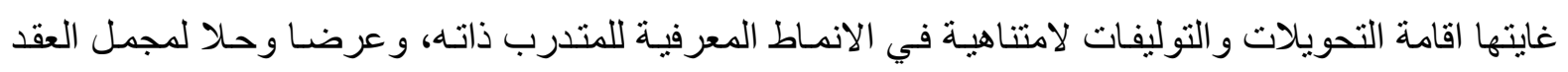
خاضعة للتحقيق و المبدأ البنيوي المتمثل في تحديد الكل للاجزاء وتحديد الأجزاء للكل، وينبغي أن لا تههل مسألة الاستقلال النسبي للاجزاء ذاتها أي قو اعد المطابقة مع مشاكل تمثل معرفة قبلية للمتدرب ذاته،(r(r) أما الأستر اتيجية الثالثة في أكتساب مهارة التفكير فوق المعرفي هي: (rr) r- تكوين خرائط ذهنية:

ان مـن المهم ملاحظـة ان أغلب إدر اكنـا عن المعـارف والتي بقيت محفوظـة في حافضتنـا المعرفيـة (المخ)، يعود الى تلك التمثلات البصرية للمعرفة، اذ لا يخفى على أحد أن مـا نر اه يمكن الاحتفاظ بـه أكثر مهـ تقر أه، اذ يبدو اسقاط الذهن نحو اشياء متخيلة وتكوين خريطة لها كأنه توجيه المادة عبر أنبوب للخروج بها من

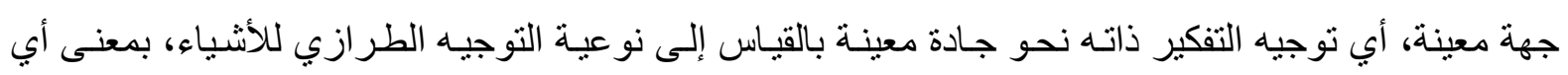
نوع من الخطاطات الذهنية يجب أستدعائها لتحل لنا المشكلة أعلاه، و هذا ضرب أخر من الأسقاط العقلي نهتم بها، و على المعلم الاهتمام به وأهتمامه يتمثل في العمل الثـامل لمد تللك الخطاطات مداً أستعاريا أنطلاقا ممـا هو 
مادي ( في قاعة الدرس) نحو ما هو غير مـادي (في ذهن المتدرب)، في مثل هذه الحالات تتطور الخطاطة الأساسية في ذهن المتدرب وتحدد مجازياً، بشكل يسمح لها بـان تقوم مقام كيانـات لم تعد ماديـة أو فضـائية

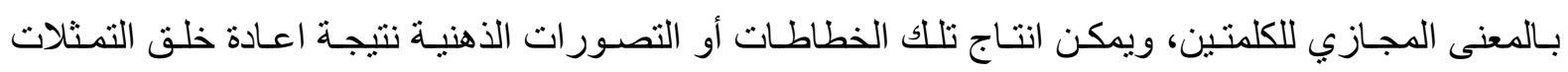
الداخلية لدى المتدرب و التي هي نتيجـة المعـارف القبلية والتي مـر بها خـلال تعرضـه للاستر اتيجيات السـابقة ويمكن تبيان خلق تلك الخطاطات الذهنية .

ان خطاطـات الصـورة الذهنيـة المنتجـة هـي في الاصـل بنى للتجربـة تتوثن في الحافظــة المعرفيـة نتيجـة التجريب المتكرر، توحد هذه النماذج لدينا بشكل ما قبل لساني، ومن ثمـة فيمكن ان تبلور وتطور بشكل معتبر

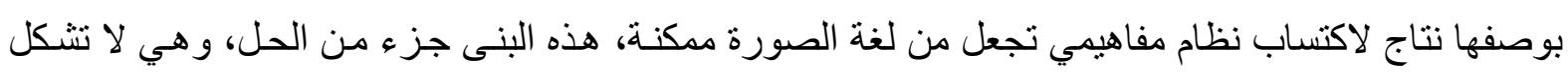

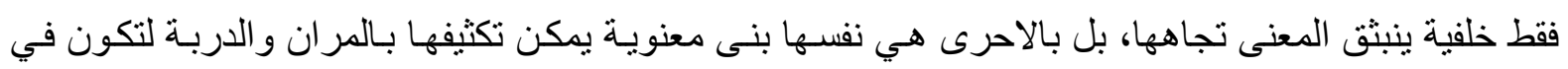
النقطة المركزية وباستخدام ألفاظ محدده مثل (يمكن للك ، تستطيع أن تحدد) ورغم إنها ألفاظ مو غلة في التجريد

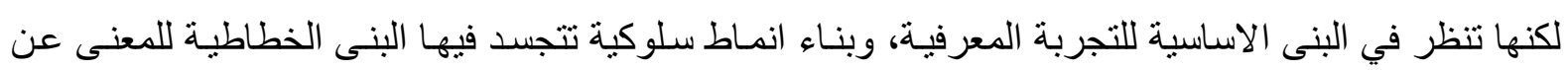
طريق جملة من المواقف والصور و المقارنات، ومقارنة هذه الانماط مع المشكلة المسلطة على الفرد . ع- تصميم خرائط للمفاهيم:

اما ما هو أكثر مناسبة لاهنماماتتا مع البنى الخطاطية للتصور ات الذهنية، فهي استخلاص المفاهيم اللفظية

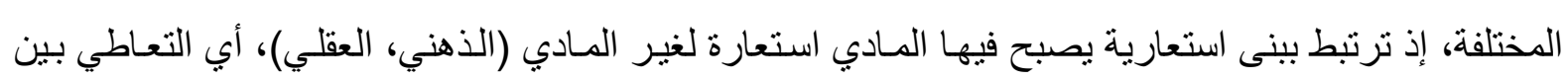

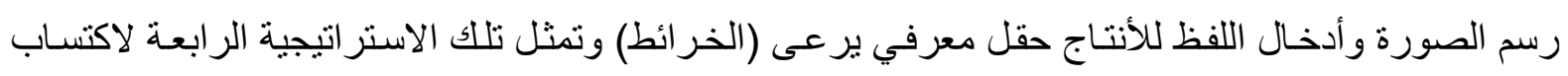
مهارة التفكير فوق المعرفي، لذا توجب على المعلم من إلزام تحريك المتدرب نحو مشكلة مـا تمتد فيها صسورة الذهن مع المعطى اللفظي للعقل، أي اعطاء وبدقة الصـورة الخطاطية للذهن للإلز ام العقل في تكوين خريطة مفاهيميـة متكاملـة، ولعل بعض المشـــل المعرفيـة يعقد حلهـا على الخـر ائط المفاهيميـة فقط دون الولوج في

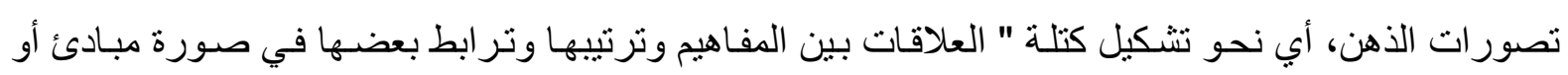
قو انين أو نظريات و المتطلبات الاجر ائية لذلك"(r') هـ تهيئة بيئة تعلم مناسبة:

تتمثل الاستر اتيجية الخامسة وهي المكملة لما سبقها، فهي تركيب يأخذ من العمق و الدلالة الكثير شـأنه شـأن أي تركيب مصدري من شأنه أن يعطي الحجة، و إن كان واحد في مجموع اربعة تتوعت خططها و آليات عملها و المقصدية من ورائها، ييقى هذا المسند أساسيا أو (أساسية)، و لا غر ابـة في مـا يعلل بـه القائلون،أن توفر بئنئة مناسبة للتعلم هي نصف التعليم، ولعل مثل هذا الاسناد تناقضه الوقائع و هذا أمر خارج عن نقطة البحث الحالي، وندا، عله من المهم توفير بيئة نقيـة صفية تتجاور فيها (التقنيات التعليميـة) مـع (كفايـات المعلم) الناتجة عن خبره ومهارة، ويتناول القيد الأول (تقنيات التعليم) كل الوسائل التكنوتعليمية التي من شـأنها تحسين مستوى المتدرب ومثال ذلك ( التعليم بمسـاعدة الحاسوب)، " أي يتم استعمال الحاسوب كآلة يحتوب على ماكنة للتعليم الذاتي حيث يقدم دروساً بشكل ضمني وذلك لتحقيق أهداف تعليمية معينة " (عَr) المتبصر في دور التكنولوجيا يجد انها

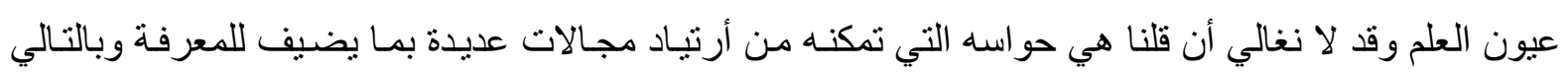


يسـاهم في تحسين النـاتج المعرفي للمتدرب، لذا يعد الحاسـب الآلي وهو وجـه رئيسي من أوجـه التكنولوجيـا عنصر اً هاما واجب توفره في الفصل الدراسي، وقد يتتوع هذا الجهاز مابين العرض فعل (العارض الألي) ومـا

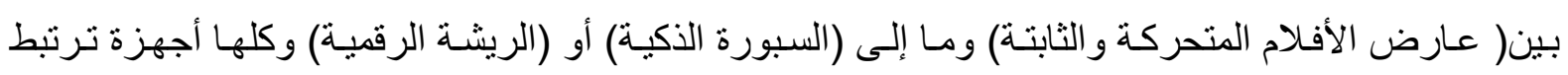
بالحاسوب تستخدم لغـة محسوبة سـاعدت في تعلم خو اص الاشكال و عرفت مجـالات لا بستطيع المعلم سبر أغو ار ها و السبب تقني يحول دون ذلك، وضبط تلك التقنيات بما يو ائم تكنولوجيا التعليم و لا يخفى علينـا الفرق بين (تقنيات التعليم) و (تكنولوجيا التعليم)، إذ أن تكنولوجيا التعليم أشمل من الأولى، " حيث أنها طريقة نظامية، منهجية تأخذ بعين الاعتبار جميع المصادر البشرية وغير البشرية واحتياجـات المتعلمين ومستوياتهم و الأهداف

التربوية،. (ro)

ما أسفر عنه الإطار النظري من مؤشرات 1 - ان التفكير ضرورة حيوية للإيمان و أكتشاف قو اميس الحياة.

r- التفكير فوق المعرفي لا ينمو تلقائيا، انما ينطلب تعليما منظما ومر انا مستمر ا. ז- دور التفكير فوق المعرفي في النجاح الدراسي الحياتي، فالتعليم المستتد لعمليات بناء تصور ات ذهنيـة منطقيـة، يمكن ان يحسن مستوى تحصيل المتعلم، ويعطيه إحساسـا بالسيطرة الواعيـة على تفكيره وخططه الذهنية.

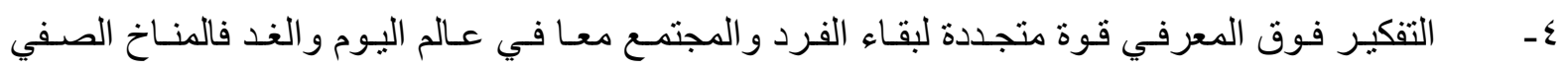
المتمركز حول المتعلم، هو التعليم النوعي الذي يوفر فرصا للتفاعل والمشاركة ويتيح للمتعلم فرصة التفكير. هـ ان تعلم التفكير فوق المعرفي يرفع من درجة الاثارة والجذب للخبرات الصفية ويجعل دور الطالب

ايجابيا وفعالا.

7- ان تعلم التفكير فوف المعرفي حاجة تفرضها تكنولوجيا المعلومـات و الاتصـالات في شتى منـاحي حياة الفرد، فالنجاح في مواجهة هذه التحديات يعتمد على كيفية استخدام المعرفة وتطبيقها. V- يمكن للمتعلم في مادة التحليل و النقد تقديم مشاريع تحتوي خططا ذهنية ناتجة عن استخدام استر اتيجيات التفكير فوق المعرفي.

1- اهمية تنوع طر ائق التدريس لضمان تنمية مهار ات التفكير فوق المعرفي للى المتعلم وتثـيع التفكير حول تفكير هم وزيادة الوعي بعمليات التنظيم الذاتية للمعلومات .

9 - يتبنى التفكير فـوق المعرفي منحسى (بياجيـه) في التطور المعرفي والذي يهـدف الى تزويـد الطلبـة

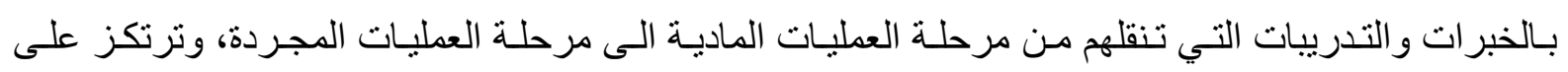
الاستكثاف ومهار ات التفكير. 
• ا- ان اعتماد استراتيجيات التفكير فوق المعرفي في تحليل الاعمـال الفنية يسـاعد على فهم المنجز الفني و ادر اكه جيداً و اكتساب الفرد فرصة للخروج من اسلبة التعليم التقليدي.

\section{الفمل الثالث (إجراءات البمث)}

أولا: مجتمع البحث ضم مجتمع البحث أعمال الفن الحديث (الرسم) .

ثانيا: عينة البحث اعتمدت الطريقة القصدية في تحديد عينة البحث (لوحة تكوين بالاحمر و الازرق و الاصفر)

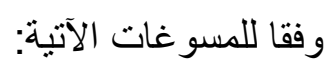
1 - اعتماد العمل الفني المذكور على افكار تتخطى الواقع الملموس الى المجرد المحسوس .

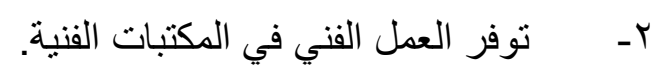
r- حصول العمل الفني على اعجاب النقاد و المختصين في الفن التشكيلي. ثالثاً: أداة البحث تم اعتماد استر اتيجيات التفكير فوق معرفي كمعايير لتحليل النص، اضافة الى اراء المختصين رابعاً: منهج البحث اتبع الباحثان المنهج التحليلي الوصفي. خامساً: تحليل عينة البحث اسم العمل :تكوين بالاحمر و الازرق و الاصفر

(Composition with Red and Blo and Yellow )

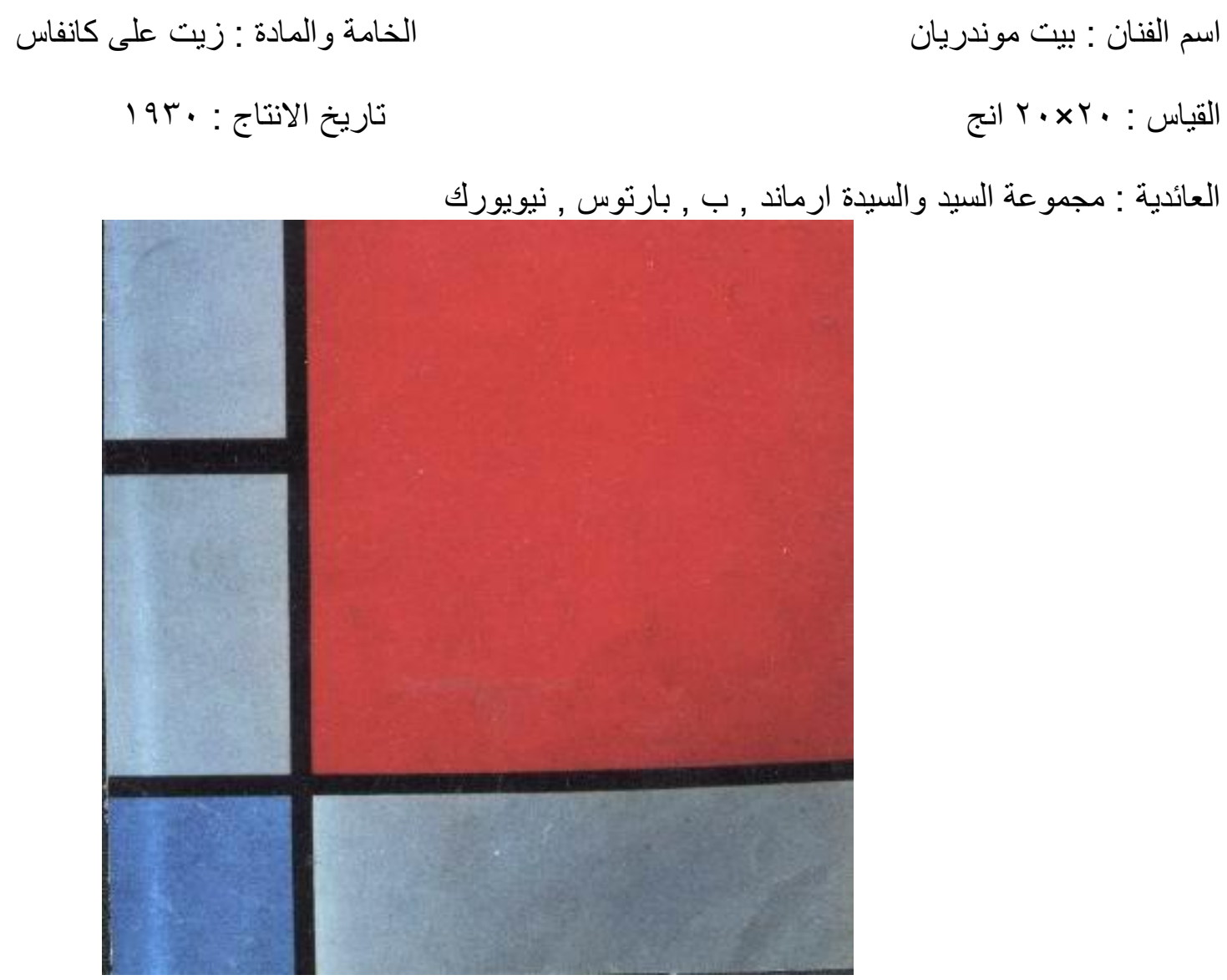


مثلت هذه اللوحة شكلين هندسيين, هما المربع المتسيد في اللوحة والمستطيل، اعلن من خلالهما (موندريان) مجافاة الواقع المادي المحسوس، على اساس النفاذ نحو عالم المثل عبر علاقات لونية حملتها الاشكال الهندسية، التي مثلت الو انها صفائح مخملية حملت الروح لعالم المثل دون ادنى اعاقة ماديـة، مستوحاة من التنـاغم اللوني ايقاعا روحيا يشكل ايقاع الحياة بأعمدة متقاطعة شكلتها الاشكال الهندسية، وكأن (موندريان) اراد طقساً يتحد مع الروح لتطهير ها وتغذيتها بالسعادة.

سعى الفنان لتقديم الكون على اساس نظرية التناغم ، كرؤية حقيقية لجمال الطبيعة كبنية اساسية للكون عبر

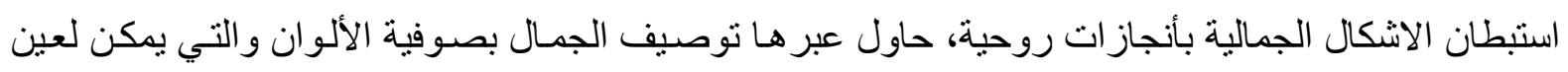
البصيرة تحقيق اقصى حالات التطهير الروحي، وهو مـا يتطلب تصعيد استارتيجيات التفكير فوف المعرفي، تفعيل حلقات روحانية تأصل الجمال بمفهوم الاشكال الهندية التي تمثل نو عا من الرياضيات التشكيلية. ان الصفة السائدة على العمل الفني هي التجريد الهندسي وبذلك يبتعد عن الاشكال الصريحة المرئية ويجعل الذات و عياً يفوق التصـور الانسـاني بـالمرة او الحزن، فضـلا عن خلق الجمـال المطلق من الروح المتسـامية المائلة نحو البساطة والزهد التي عبر عنا (موندريان) عبر الخطوط العمودية البسيطة والالوان الزاهية، محيطسا بهـا بنظام شـامل موظفاً التعامد في الخطوط العموديـة والافقيـة قوة تحرك العـالم نحو التجريب و الابتعـاد عن ولن الحسي الزائل، وللغرض نفسه تختزل الالوان لتقتصر على الالوان الاساسية مع الاسود والابيض او الاشتغال

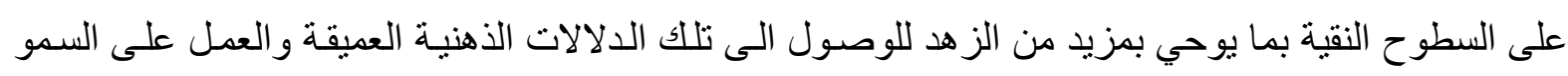

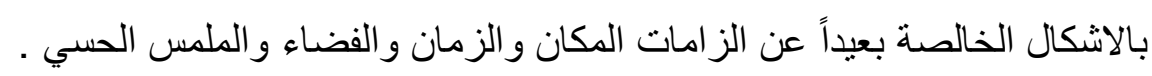
يتبن من ذلك مدى الارتكاز الى قوة التفكير فوق المعرفي بمستو اه الخالص و تحقيقه لتطبيقات الصسورة و

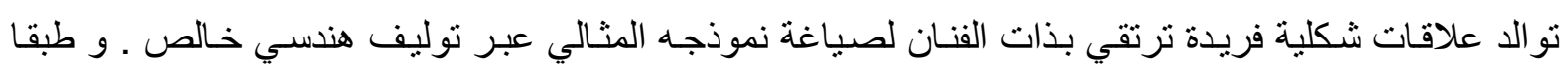

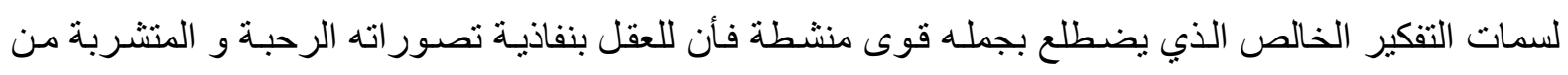
علاقاته الحسية المحضـة قد عزز النظـام التجريدي الصـارم , و ان اضـفاء العمـق الروحي و نوطيد الصـلة بالمطلق يتطلب قوى فوق عقلية تمتزج بمديات تخيلية تعين العقل على تجاوز صـلاته الموضو عية و الماديـة وحمل الصورة لبث فكرتها الجو هرية بشمول و ابداعها في الثكل الخالص الذي بحقق اكتفاءه بذاته بأيهاماتـه و

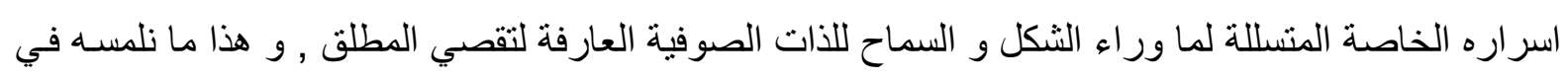

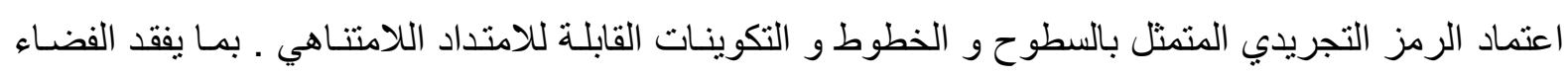

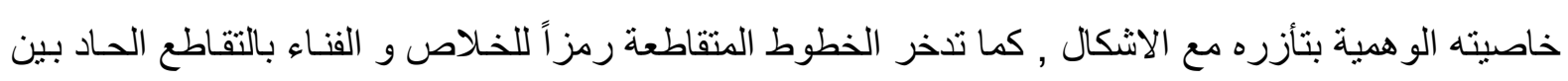
الحياة و الموت و الالتقاء الروحي بالمطلق ـ و هذا ما يذكر بالبنائية الهندية للزخرفة الاسـلامية و توسمها بآلية تطبيقية يتمكن المتلقي عبر التفكير الفوق معرفي فناء ذاته في المطلق .

ان ( موندريان ) يحقق بجـلاء توصيفات التفكير فوق المعرفي الخـالص و تموضـعاته في اثـكال مثاليـة افلاطونية وكانتية تتجاوز الحس المتغير والمادي الطاريء و كل ما في الوعي و اللاو عي من صلة بـالغرائزي او الوجداني العابر , و بمنحى عقلي تخيلي يزدان بالوقار الشكلي الخالص. 
الفنصل الرابع

اولاً: النتائج

1- يثكل التفكير فوق المعرفي البنيـة المعرفية الأساسية التي ينطلق منها الرسم الحديث, على مختلف

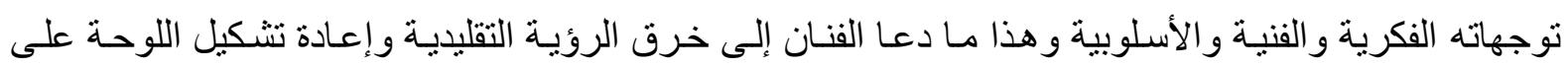
أساس من العلاقات الكلية المجردة.

r- ت تساوى استر اتيجيات التفكير فوق المعرفي ومستوياته مع مختلف اتجاهات الرسم الحديث وتحو لاته.

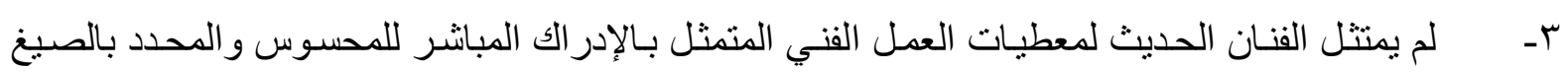
الزمانيـة والمكانيـة, بـل استعاض عن الرؤيـة الحسية المبانـرة برؤيـة حدسية تقوم على أسـاس ادر الك مفـاهيم وصور كلية ذات أبعاد روحية ووجدانية وهذا ما ترتب عليه ابتعاده عن الموضو عات الواقعية.

ع- يعد التفكير فوق المعرفي مستحصل مباشرة من قوى عدة، والمعرفة الحسية واحدة من هذه القوى،

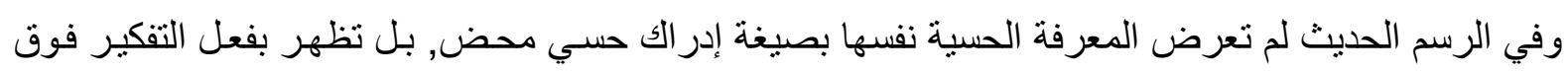
المعرفي متضامنة مع قوى عقلية وتخيلية ووجدانية. ــ تعد المخيلة القوة المعرفية السـائدة على المعرفيات الاخرى التي تتشكل منها بنيـة التفكير في الرسم الحديث.

آ- شكلت القوى العقلية والتصورات الناتجة عنها, إحدى القوى الفاعلة في بنية العمل في الرسم الحديث, و انعكاسها على بنية التشكيل وقيادة بنائية الاشكال و علاقاتها المجردة وصو لا الى صورة المثال العقلي المجرد.

$$
\begin{aligned}
& \text { وتتجلى تصورات العقل عبر الثكل الحسي } \\
& \text { ثناتياً: الاستنتاجات: }
\end{aligned}
$$

في ضوء النتائج التي توصل اليها البحث. يستنتج الباحثان جملة استنتاجات،وهي كما يأتي:

ا - على الرغم من افادة الرسـام الحديث من الطروحات الفلسفية والجمالية، الى ان افكاره بقيت مستقلة وحرة في التعبير عن ذات الفنان ، وهذا يعني اصسالة التفكير فوق معرفي بوصفه تكثنفاً ذاتيـاً صميمياً وفريداً غير قابل للتطابق او التكر ار.

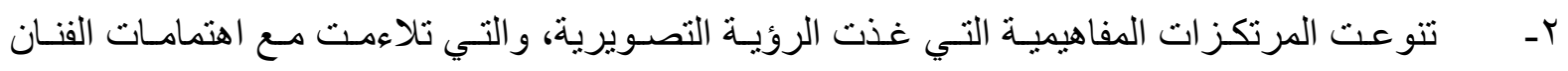
الحديث بتلك المرتكزات. كالتأثر بالكثـوفات العلميـة للضوء عند الانطباعيين، او الافادة من مظـاهر التطور التكنولوجي لدى بعض التكعيبيين، او اتباع النزعة الروحية لدى التجريديين. او تبني طروحات التحليل النفسي لاى السرياليين... هذا التنوع لايتناقض مع التعبير عن تلك الرؤية التي خرج بها التفكير فوق معرفي ومحاولنة خلق معادل صوري لتلك الاهتمامات غير خاضع للمعايير الحسية والموضوعية. 
r- اتاحت معرفية التفكير فوق المعرفي لدى المتلقي فرصة إطلاق معرفته بالاشياء وبخفايا الذات وتمكينه من السيطرة على اهتماماته الواعية واللاو اعية والتعبير عن ذلك بصورة نقية وفريدة، ثالثاً: التوصيات

1- توسيع دائرة البحث في استراتيجيات التفكير فوق المعرفي، ليشمل العمل التشكيلي الحر غير المقيد بالسياقات الاكاديمية.

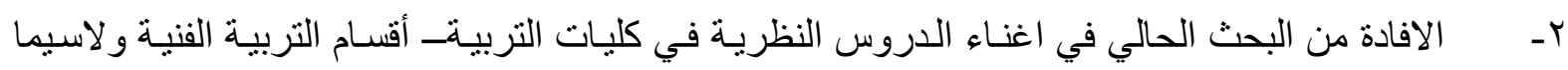
مادة علم الجمال - كطروحات جمالية قابلة للنطبيق r- الإفادة من البحث الحالي من قبل طلبة الدراسات العليا المتخصصين بالجماليات و الفنون. المقترحات: يقتر ح الباحثان الآتي: 1 - دراسة آليات التحليل على وفق استراتيجيات التفكير الناقد. r- در اسة آليات التحليل على وفق استر اتيجيات التفكير الإبداعي. r- دراسة آليات التحليل على وفق استر اتيجيات التفكير ألابتكاري.

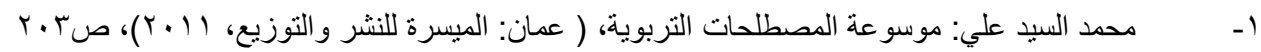

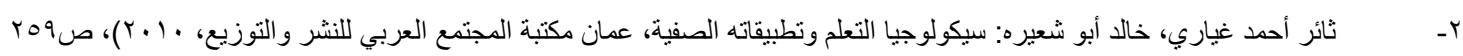

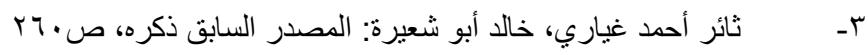

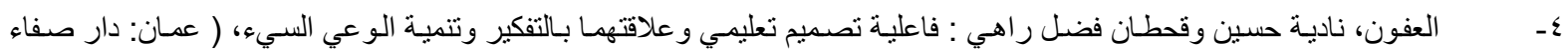

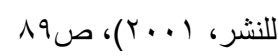

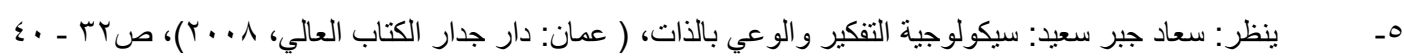

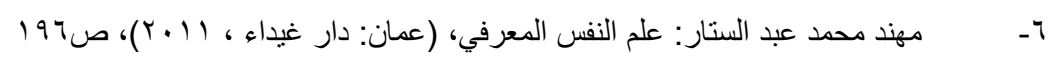

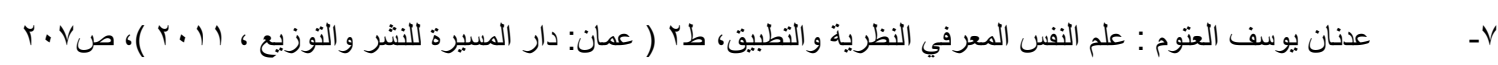

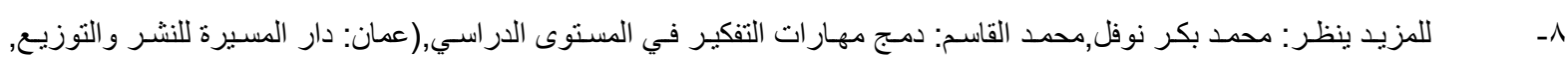
rV. - rTr ص, (r.1)

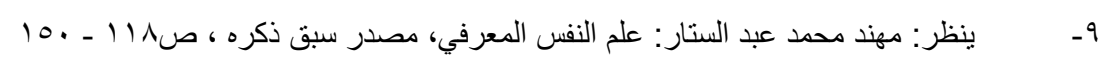

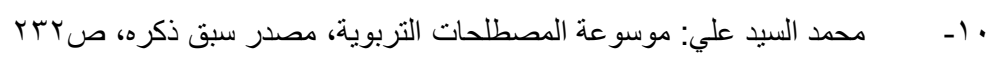

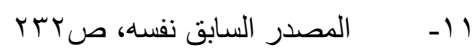

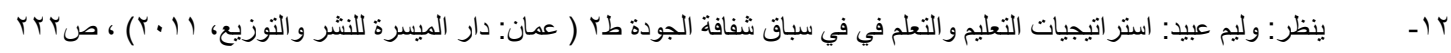

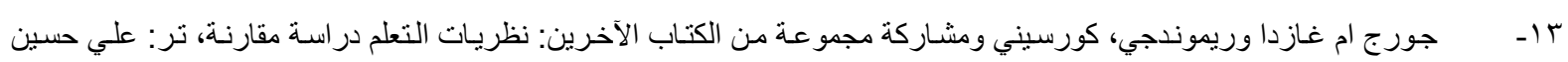

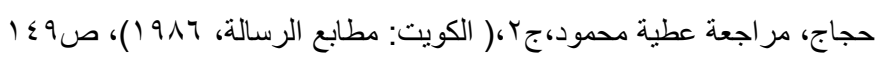

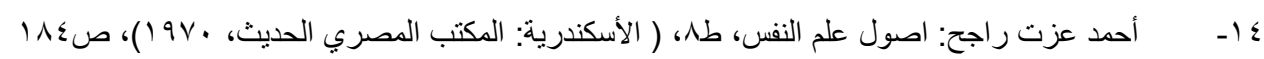

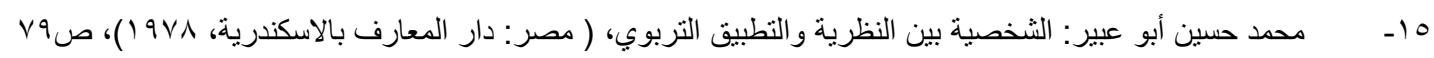

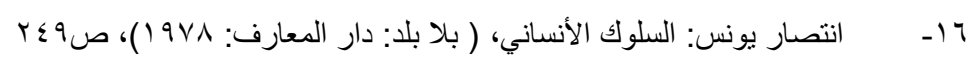

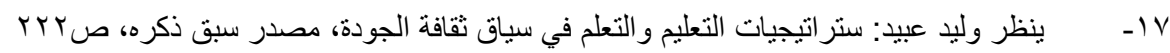

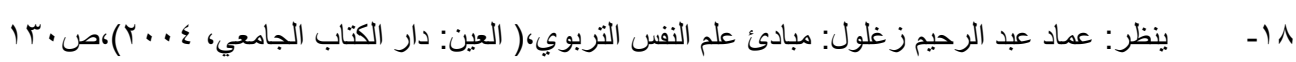

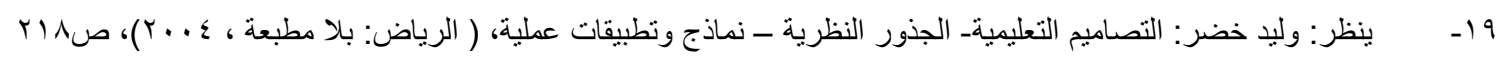

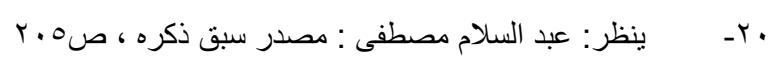




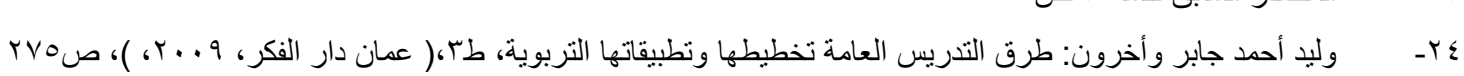

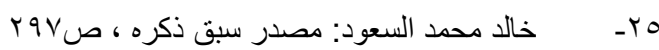

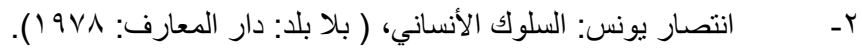

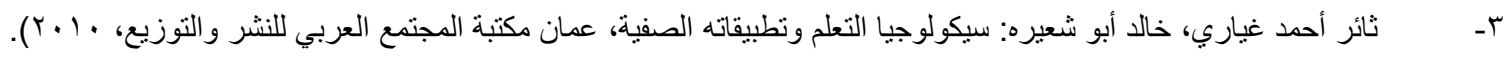

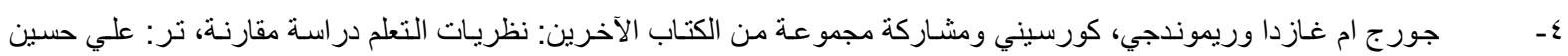

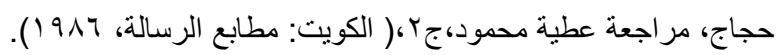

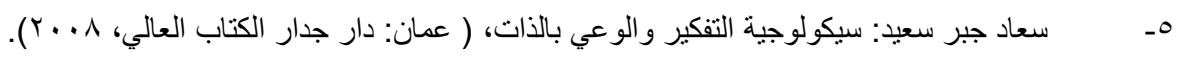

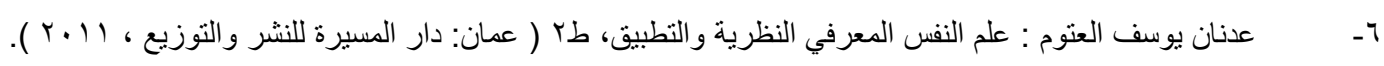

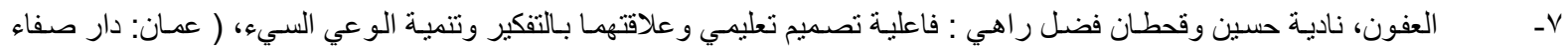

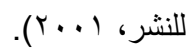

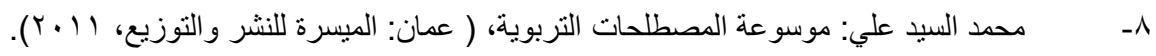

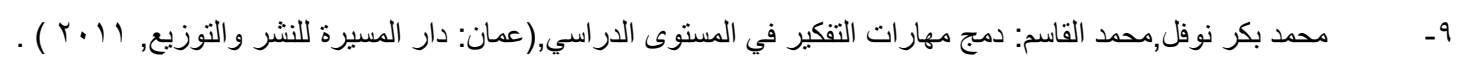

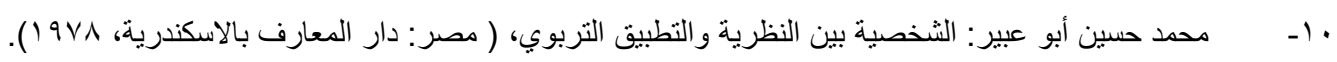

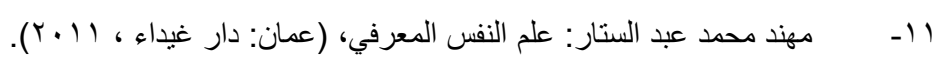

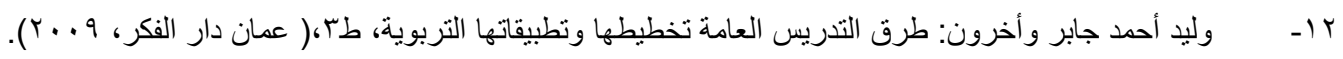

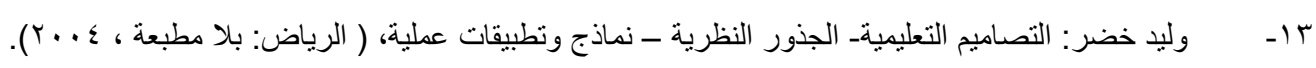

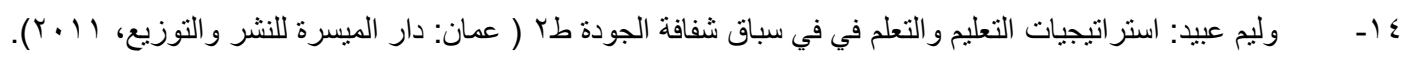

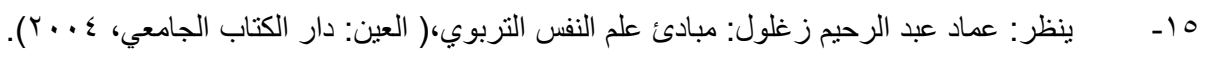

